\title{
The critical role of the industrial sector in reaching long-term emission re- duction, energy efficiency and renewable targets
}

\author{
Birgit Fais ${ }^{1}$, Nagore Sabio, Neil Strachan \\ UCL Energy Institute, University College London
}

\begin{abstract}
This paper evaluates the critical contribution of the industry sector to long-term decarbonisation, efficiency and renewable energy policy targets. Its methodological novelty is the incorporation of a process-oriented modelling approach based on a comprehensive technology database for the industry sector in a national energy system model for the UK (UKTM), allowing quantification of the role of both decarbonisation of upstream energy vectors and of mitigation options in the industrial sub-categories. This enhanced model is then applied in a comparative policy scenario analysis on the various target dimensions on emission mitigation, renewable energy and energy efficiency at both a national and European level. Ambitious emission cuts in the industry sector of up to $77 \%$ until 2050 compared to 1990 can be achieved. Moreover, with a reduction in industrial energy demand of up to $31 \%$ between 2010 and 2050, the sector is essential for achieving the overall efficiency commitments. The industry sector also makes a moderate contribution to the expansion of renewable energies mostly through the use of biomass for lowtemperature heating services. However, additional sub-targets on renewable sources and energy efficiency need to be assessed critically, as they can significantly distort the costefficiency of the long-term mitigation pathway.
\end{abstract}

Keywords: Energy system analysis; industry sector; emission reduction; renewable energies; energy efficiency; policy interaction

\section{Introduction}

In recent years, the number of national greenhouse gas (GHG) emissions mitigation targets and strategies has increased considerably accompanied by a trend to implement these targets through a mix of different, often sector-specific, policy instruments [1]. In addition to limits on GHG emissions, many countries have formulated targets for the use of renewable energies and progress in energy efficiency making the issue of target and policy coordination essential [2]. Within the global effort of keeping the temperature rise below $2^{\circ} \mathrm{C}$, the UK introduced the Climate Change Act in 2008. Through this legally binding framework the UK has formally committed to a GHG emission reduction of $80 \%$ by 2050 compared to the level in 1990 and a portfolio of instruments, including an electricity market reform, energy taxes as well as incentive measures for renewable heat and energy efficiency in buildings has been introduced ([3] \& [4]).

In many past analyses on the possible pathways to reach these targets, a strong focus has been put on the evaluation of the mitigation potentials on the energy supply side, particularly the decarbonisation of the electricity sector. Demand-side analyses and modelling has generally focused on the more homogenous transport and buildings sectors. Yet, it is essential to consider the industrial sector in its contribution to energy policy goals and its interactions with the rest of the energy system.

1 Corresponding author: Birgit Fais, email: b.fais@ucl.ac.uk 
At the global level, the industrial sector is responsible for over a third of energy demand and a slightly higher emissions share ([5] \& [6]). In its $5^{\text {th }}$ Assessment Report, the IPCC placed the industrial sector as the most pollutant end-use sector, even before buildings and transport [7]. In the UK, the industrial sector currently accounts for about a quarter of total greenhouse gas emissions (including indirect emissions from electricity use) and almost a fifth of final energy consumption with the most energyintensive subsectors (iron and steel, cement and other non-metallic minerals, non-ferrous metals, pulp and paper, chemicals) being responsible for more than two thirds of these emissions [8]. In the future, the industry sector will face the dual challenge of implementing low energy and low carbon technologies while simultaneously maintaining international competitiveness. In addition to the national energy and climate policy, the future development of the UK industry sector is also affected by the EUwide legislation which, in addition to emission reduction, sets explicit targets for the progress in energy efficiency and the use of renewable energies across the whole energy system ([9] \& [10]).

As discussed in detail in Chapter 2, assessing the possible contribution of the industry sector to a multi-faceted energy transition poses a considerable challenge given the heterogeneity of the sector in terms of the manufactured products, the production processes and technologies applied, all within a systems context of competing resources and alternate end-use applications of energy vectors. Bottomup energy system models constitute powerful tools to analyse long-term emission reduction pathways in a systematic manner with the advantages of including a high level of technological detail and taking all interactions within the energy system into account. Detailed modelling of actual production processes and accounting for the substantial differences between industrial subsectors is a bespoke process that can yield fresh insights, although often with exogenous assumptions on energy systems interactions.

This paper has two primary objectives:

64 1) to present a novel process-oriented modelling approach for the industry sector (the disaggregated hybrid module or DHM) integrating a comprehensive bottom-up technology database into a newly developed national energy system model (UK TIMES Model or UKTM); and

2) to assess the UK industry sector's possible long-term contribution system-wide targets within the scope of a comparative scenario analysis of overlapping policies of decarbonisation, efficiency and renewable energy.

Chapter 2 provides a review on the current modelling representation of the industry sector in an energy system context. Focusing on the UK as a modelling and policy exemplar, after a short description of UKTM, the new methodology for representing the industry sector in a more disaggregated manner is presented in Chapter 3. Chapter 4 outlines the overlapping policy analysis and the comparative scenario assumptions. The main results of the scenario analysis, focusing on the industry sector, are out- 
 \\ 2. Modelling of the industry sector in an energy system context ${ }^{2}$}

78 Since the industry sector is a highly heterogeneous sector in terms of its energy use, modelling the future development of industrial energy demand as well as policy design is a substantial challenge [11]. Other energy end-use sectors, especially the residential and transport sector are in comparison more homogenous with respect to their energy service demands, such that modelling approaches in whole system models are generally more straightforward (cf. for example [12], [13], [14] for the residential sector; and [15], [16], [17] for the transport sector).

A variety of recent studies have evaluated the energy savings and emission reduction potentials of different industrial subsectors from a sector-specific perspective (cf. for example [18], [19], [20], [21], [22], [23] \& [24]). These analyses explore the industrial production routes in great detail, but look at the industrial subsectors in isolation. However, in order to evaluate the industry sector's long-term contribution to emission mitigation and other energy policy targets, a more comprehensive modelling approach is required.

On the other hand, bottom-up energy optimisation models which cover the entire energy system have long been applied to determine cost-efficient and consistent long-term pathways for a low-carbon energy transition and to analyse interactions and the competition for resources as well as low-carbon energy vectors in the system. Yet, given the scope and complexity of these models, traditionally a relatively simple modelling approach for the industrial sector based on the different types of energy service or end-use demands has often been chosen (see for example the representation in UK MARKAL [25] or in the global ETSAP-TIAM model [26]).

This approach is generally characterized by the use of abstract process technologies which provide different types of energy services (like low or high temperature heat, motor drive, drying, etc.). That means that instead of representing the actual production steps and specific technologies required to produce a certain final product, the energy service demands and their potential provisions through different fuels are represented in a generic manner (usually using the same cost and technology assumptions for each sub-sector). Each process technology has one specific fuel as input which is used to produce one specific energy service. In a second step, a dummy demand technology (not representing an actual production process) aggregates the various energy service demand categories (usually with fixed shares for each category) in order to produce the final end-use demand (usually specified in

2 This short review focuses on the representation of the industrial sector in technology-oriented, bottom-up energy system models. There are two additional main thrusts of industrial energy modelling that are important but are not the focus of this paper. Firstly, multi-regional input-output models analysing issues of direct versus indirect emissions and the possible offshoring of energy use and resultant emission leakage (cf. for example [31], [32] \& [33]). Secondly, macroeconomic modelling approaches focusing on the wider macro-economic implications of changed prices in the industrial subsectors and potential restrictions on industrial output (cf. for example [34], [35] \& [36]). 


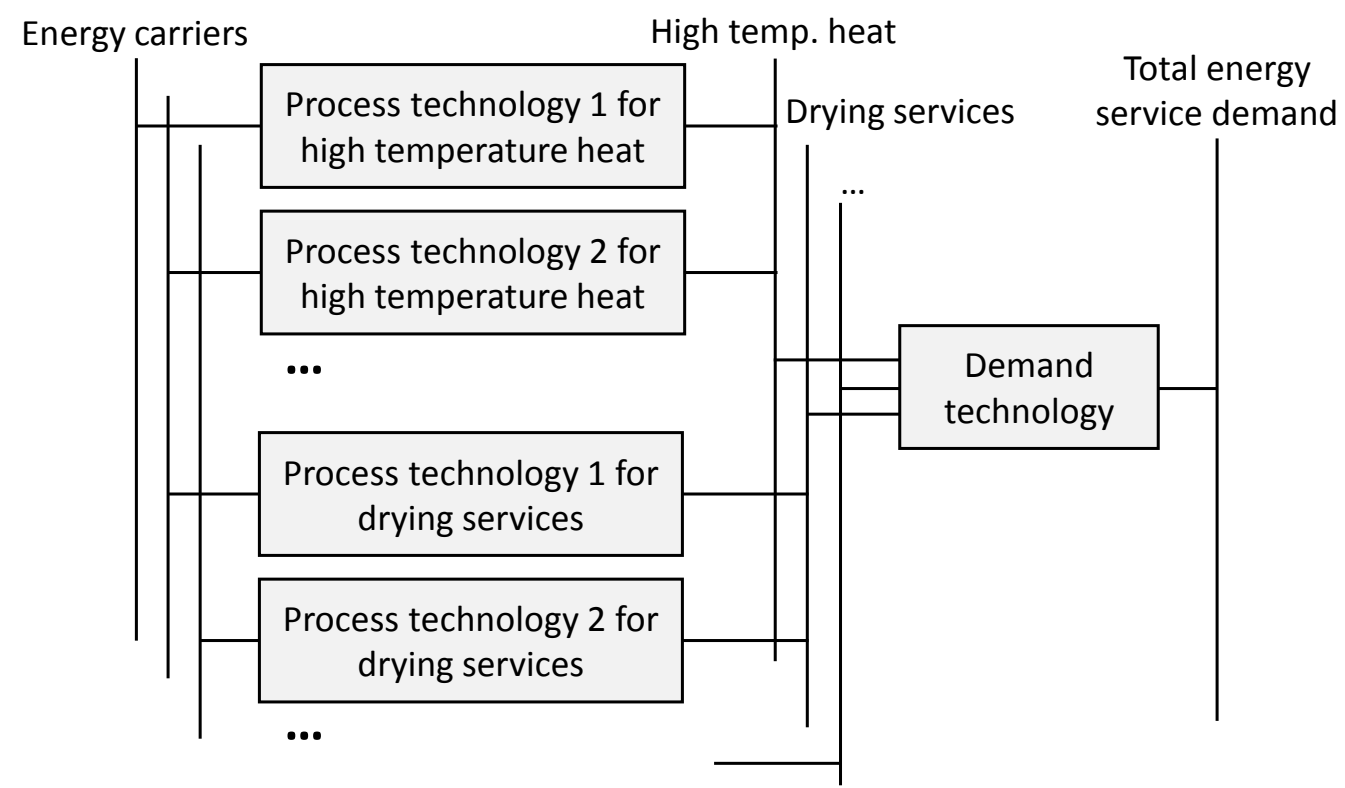

Figure 1: Example of an industrial modelling approach based on energy service demands

The advantage of modelling by end-use demands is that the sector can be represented through a small number of components, while still allowing for the characterisation of energy uses and cross-sectoral substitutions. This approach is mainly suited to evaluate the potential for fuel switching in the industry sectors. However, several shortcomings need to be taken into account when applying this methodology:

- Given that the actual process technologies in the various industrial subsectors are not explicitly modelled, important technological constraints can often not be accounted for or only approximated with this approach. For example, the use of the electric arc furnace route in steel-making is limited by the availability of metal scrap.

- This also implies that radical technological changes in the production processes, which are especially needed in the case of ambitious emission reduction targets, cannot directly be included in the model approach. This drawback becomes particularly evident when thinking about technologies with carbon capture and storage (CCS).

- In addition, if the actual process technologies are not modelled, it is difficult to account for process emissions and, more importantly, to include mitigation options for these emissions.

- Although energy systems models focus on energy flows, it is evident that materials are an important part of the system, especially in the industry sector. Such material flows can only be represented when the actual process technologies are modelled.

In light of these problematic issues, attempts have been made in recent years to improve the representation of the industry sector in bottom-up energy system models. In general, it can be observed that modelling improvements are strongly focused on the energy-intensive subsectors. The European energy model PRIMES still represents the industry sector through end uses, but includes a large variety and differentiates them by subsector (e.g. sinter making in iron and steel) [27]. The energy-economy modelling system NEMS uses a detailed process flow approach for energy-intensive manufacturing industries with homogenous products, while for more heterogeneous subsectors the end-use approach is chosen [28]. The ETP model contains a stock accounting simulation model for five energyintensive sectors with a detailed representation of the process technologies in the different production routes [29]. Similar to the new approach chosen for UKTM described below, the JRC-EU-TIMES 
model represents energy-intensive industries in a detailed, process-based manner and uses a generic structure based on end uses for the remaining industrial subsectors [30]. In all cases it is, however, difficult to obtain information on the underlying cost and technology assumptions used for the industrial modelling approaches.

The novelty of the modelling approach with UKTM consists mainly in its link to a comprehensive process-oriented database on industrial production processes and future potentials of innovative technologies. Thus, UKTM does not only provide a representation of the industrial sector with a higher level of detail on production technologies than most current energy system models, but this technology data is based on a consistent and publicly available database. This also makes it easier to replicate the approach in other geographical energy system contexts.

\section{Model and methodological approach}

\subsection{The national energy system model UKTM}

The quantitative scenario analysis is conducted with the new national UK TIMES energy system model (UKTM). UKTM has been developed at the UCL Energy Institute over the last two years as a successor to the UK MARKAL model [25], It is based on the model generator TIMES (The Integrated MARKAL-EFOM System), which is developed and maintained by the Energy Technology Systems Analysis Programme (ETSAP) of the International Energy Agency (IEA) [37].

UK MARKAL and now UKTM have been major underpinning analytical frameworks for UK energy policy making and legislation from 2003 to 2013 ([38], [39], [40] \& [3]). With the aim to increase the transparency in energy systems modelling and to establish an active user group - including key decision makers - an open source version of UKTM will be released in 2015 which will be updated on a regular basis. Moreover, UKTM will continue to be the central long-term energy system pathway model used for policy analysis at the Department of Energy and Climate Change (DECC) and the Committee on Climate Change (CCC), including the $5^{\text {th }}$ Carbon Budget Report which sets the limit on GHG emissions in the UK for the period from 2028 to 2032 and feeds into the UK's negotiating position at the United Nations Climate Change Conference (COP 21) in December 2015. First research outputs based on UKTM are [41] and [42].

UKTM is a technology-oriented, dynamic, linear programming optimisation model representing the entire UK energy system (as one region) from imports and domestic production of fuel resources, through fuel processing and supply, explicit representation of infrastructures, conversion to secondary energy carriers (including electricity, heat and hydrogen), end-use technologies and energy service demands. Generally, it minimizes the total welfare costs (under perfect foresight ${ }^{3}$ ) to meet the exogenously given sectoral energy demands under a range of input assumptions and additional constraints and thereby delivers an economy-wide solution of cost-optimal energy market development.

The model is divided into three supply side (resources \& trade, processing \& infrastructure and electricity generation) and five demand sectors (residential, services, industry, transport and agriculture). All sectors are calibrated to the base year 2010, for which the existing stock of energy technologies and their characteristics are taken into account. A large variety of future supply and demand technologies are represented by techno-economic parameters such as the capacity factor, energy efficiency,

3 UKTM is run in a dynamic manner. The assumption of perfect foresight means that all investment decisions in each period are made with full knowledge of the input assumptions for future periods (e.g. on fuel prices or technology costs). 
lifetime, capital costs, O\&M costs etc. Moreover, assumptions are laid down concerning energy prices, resource availability and the potentials of renewable energy sources, etc. UKTM has a time resolution of 16 time-slices (four seasons and four intra-day times-slices). In addition to all energy flows, UKTM tracks $\mathrm{CO}_{2}, \mathrm{CH}_{4}, \mathrm{~N}_{2} \mathrm{O}$ and HFC emissions. For more information on UKTM see [43].

\subsection{New modelling approach for the industrial sector: disaggregated hybrid module}

The new industrial sector module in UKTM is composed of eight subsectors ${ }^{4}$. A more detailed modelling approach has been incorporated for the most energy-intensive branches of the UK industry, while for the remaining sectors the already mentioned conventional methodology based on aggregated service demands (ASD) is maintained. See Figure 2 for a simplified structure of UKTM and the new industrial modelling approach.

The development of a more detailed, process-oriented modelling approach for the industry sector depends hugely on the availability of comprehensive and reliable data on current and future industrial production process. The new industrial module in UKTM is based mainly on the technological and economic data provided in the Usable Energy Database (UED). It provides both the baseline energy use and emissions by technology in 2010 and a wide range of possible future improvement technologies for a number of energy-intensive industry sectors in the UK [44] $]^{5}$. One of the major challenges in linking the UED to UKTM was to select the most relevant future technology options (as the UED provides up to 50 options per sub-sector) and represent them correctly in an energy systems modelling context. This was done on the basis of their energy or emissions saving potential and the associated costs. Highly uncertain technologies have been constrained or fully excluded from the modelling approach.

Based on the UED, the energy-intensive industry sectors iron \& steel, cement and paper are modelled in a process-oriented manner, meaning that the actual production processes are represented in the model. With respect to future technology choices, different options to reduce energy demand and emissions are taken into account: (1) exploitation of already commercial technology options with higher energy efficiency or less carbon-intensive energy inputs, e.g. a stronger switch to the electric arc furnace steelmaking route, the use of precalciners and kilns with increased waste utilisation in cement production or autothermal reforming in ammonia production; (2) improvement potentials for already installed process technologies, e.g. heat recovery in different sectors, scrap preheating in electric arc furnaces or online moisture management in the paper industry and (3) more radical process changes, e.g. carbon capture and storage technologies (CCS), low-carbon cement options, alternative steelmaking routes (MIDREX, HISARNA, etc.) or Fischer-Tropsch processes in steam cracking. Growth constraints are put on all major technology groups to ensure realistic future technology deployment rates.

4 Mining and refining processes are included in the resources \& trade and the processing sectors of UKTM.

5 The UED can be downloaded here: http://data.ukedc.rl.ac.uk/cgi-bin/dataset_catalogue/view.cgi.py?id=15 


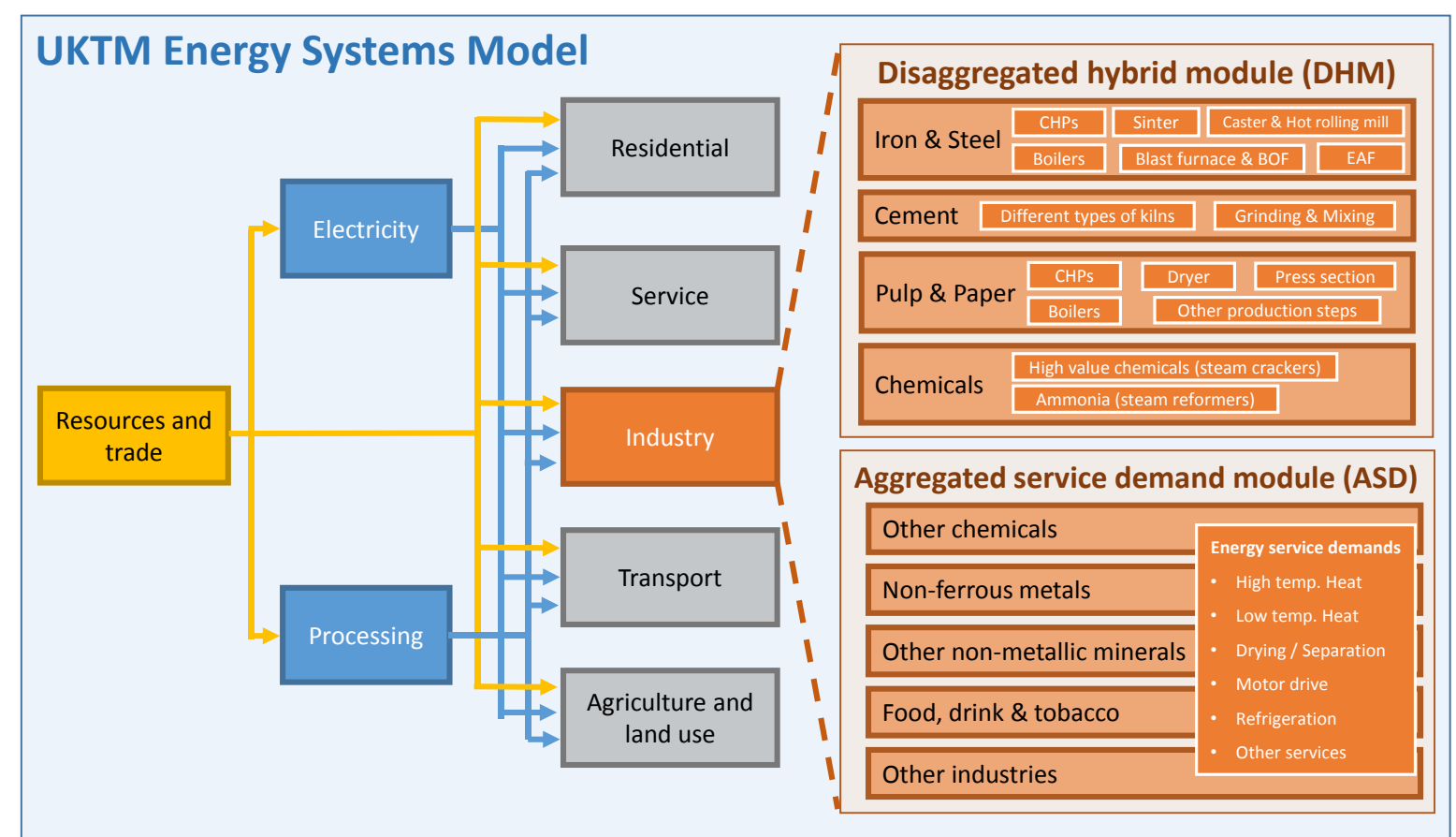

Figure 2: Overview of the UKTM Energy Systems Model and the Integration of the new industrial modelling approach

The chemicals sector is highly heterogeneous. In the model, it has been decided to separate the production of high value chemicals (olefins) and ammonia and model these subsectors in a process-based manner. High value chemicals are responsible for about a quarter of energy demand of the entire chemicals sector and also consume a high share of fuels for non-energy use. The separate modelling of ammonia is of particular importance to take the process-related emissions of this subsector into account.

The remaining industrial subsectors (other chemicals, non-ferrous metals, other non-metallic minerals, food, drink and tobacco as well as other industries), which are either comparatively small (in terms of their energy demand and/or GHG emissions) or less energy intensive and have a highly heterogeneous production structure, are modelled using the traditional ASD approach described above based on different energy service demand categories. The data on the current industrial energy demand according to different energy service categories is taken from [45]. In the model, a differentiation is made between the six most important energy services (high temperature processes, low temperature processes, drying/separation, motor drive, refrigeration, and others). The technology and cost data for the various process technologies in these subsectors are mainly taken from the previous UK MARKAL model with updated cost data for low temperature heat and drying/separation processes.

\section{Policy assumptions and scenario description}

The scenario analysis with UKTM is based on standard socio-economic assumptions, most importantly an average GDP growth rate of $2.4 \%$ p.a. [46] and a rise in population of $0.5 \%$ p.a. [47] over the period from 2010 to 2050. From that, consistent drivers for the various energy service demands in the end-use sectors are developed taking also a variety of national forecasts on the development of household growth, employment, transport demand, etc. into account. The demand projections for the industry sector are mainly based on the econometric DECC Energy and Emissions Projections model 
(EEP) ${ }^{6}$ (Error! Reference source not found.). It has to be noted that in case of the process-oriented sectors the demand projections describe changes in aggregate output, while in the case of the remaining sectors both changes in output and energy intensity are taken into account.

Table 1: Demand projections for the industry sector in UKTM (based on the DECC EEP model)

\begin{tabular}{|l|cccccc|}
\hline \multicolumn{1}{|c|}{ Demand driver, $\mathbf{2 0 1 0}=\mathbf{1}$} & $\mathbf{2 0 1 0}$ & $\mathbf{2 0 1 5}$ & $\mathbf{2 0 2 0}$ & $\mathbf{2 0 3 0}$ & $\mathbf{2 0 4 0}$ & $\mathbf{2 0 5 0}$ \\
\hline Iron and steel & 1 & 0.92 & 0.90 & 0.87 & 0.83 & 0.80 \\
Cement & 1 & 1.01 & 1.01 & 1.00 & 0.97 & 0.89 \\
Paper and paper products & 1 & 0.90 & 0.87 & 0.81 & 0.75 & 0.70 \\
Chemicals & 1 & 0.94 & 0.92 & 0.89 & 0.87 & 0.84 \\
Non-ferrous metals & 1 & 0.92 & 0.90 & 0.87 & 0.83 & 0.80 \\
Other non-metallic minerals & 1 & 1.01 & 1.01 & 1.00 & 0.97 & 0.89 \\
Food, drink and tobacco & 1 & 0.92 & 0.96 & 1.03 & 1.12 & 1.20 \\
Other industries & 1 & 0.84 & 0.83 & 0.80 & 0.78 & 0.75 \\
\hline
\end{tabular}

The assumptions for fossil fuel prices are based on results from the global energy system model TIAM-UCL [48] with a world market price for crude oil of $90 \$ 7$ per barrel in 2050. The availability and costs for bio-energy, both domestic resources and imports, are adopted from [49] (medium assumptions of the Extended Land Use Scenario). With respect to future technology costs, exogenous learning rates are applied, especially in the case of less mature electricity and hydrogen technologies, assuming that the UK is a price taker for globally developing technologies. A global discount rate of $3.5 \%$ p.a. for the first 30 years and 3\% afterwards is used based on [50]. In addition, sector-specific discount rates are included to reflect the varying private costs of capital by sector (10\% for all energy supply sectors as well as the industry, agriculture and service sectors, $7 \%$ for transport and 5\% for the residential sector; based on [51] and [52]). In order to take into account adjustments in energy service demand due to changes in energy prices, the elastic demand variant of TIMES is used [37]. The longrun own-price elasticities that are attached to the demand categories are based on [53] and range between -0.03 and -0.7 .

With the aim to assess the contribution of the UK industry sector to major energy and climate policy targets, the comparative scenario analysis takes both the national climate policy framework and the overarching policy targets on EU level into account. In light of the rising number of targets and measures in energy and climate policy, the issue of policy interactions gains in importance and must be accounted for when aiming at a coordinated and consistent policy mix [54]. Modelling multiple policy targets and especially instruments increases the complexity of the scenario analysis but provides valuable insights ([55] \& [56]). The policy scenarios in the analysis at hand are constructed such that the interactions between the overall GHG reduction target and the sub-targets on energy efficiency and renewable energies can be evaluated (see Table 2).

\footnotetext{
6 A description of the DECC EEP model can be found in [65]. The actual model runs underlying the demand projections for UKTM have not been published.

7 All monetary values stated in this paper are in real terms, with 2010 as base year.
} 
Table 2: Policy scenario overview

\begin{tabular}{|c|c|c|c|c|}
\hline $\begin{array}{l}\text { Scenario } \\
\text { name }\end{array}$ & $\begin{array}{l}\text { National } \\
\text { GHG reduc- } \\
\text { tion target }\end{array}$ & $\begin{array}{l}\text { EU Emission } \\
\text { Trading }\end{array}$ & $\begin{array}{l}\text { Energy effi- } \\
\text { ciency target }\end{array}$ & $\begin{array}{l}\text { Renewables } \\
\text { target }\end{array}$ \\
\hline BASE & \multicolumn{4}{|c|}{ No long-term policy targets } \\
\hline GHG & \multirow{4}{*}{$\begin{array}{l}-80 \% \text { until } \\
2050 \text { com- } \\
\text { pared to } \\
1990\end{array}$} & - & - & - \\
\hline GHG_RE & & \multirow{3}{*}{$\begin{array}{l}\text { Carbon prices } \\
\text { for the ETS } \\
\text { sector and the } \\
\text { Non-ETS sec- } \\
\text { tor until } 2030\end{array}$} & - & $\begin{array}{c}\text { Renewable share: } 15 \% \text { in } 2020, \\
20 \% \text { in } 2030,50 \% \text { in } 2050\end{array}$ \\
\hline GHG_EE & & & \multirow{2}{*}{$\begin{array}{l}\text { Annual reduc- } \\
\text { tion rate for } \\
\text { final energy } \\
\text { consumption: } \\
0.9 \%\end{array}$} & - \\
\hline GHG_RE+EE & & & & $\begin{array}{c}\text { Renewable share: } 15 \% \text { in } 2020 \\
20 \% \text { in } 2030,50 \% \text { in } 2050\end{array}$ \\
\hline
\end{tabular}

In addition to the baseline scenario BASE, which assumes no long-term energy or climate policy targets and is used as a benchmark, Table 2 details four low-carbon scenarios with varying assumptions on the consideration of the EU targets on emission mitigation, energy efficiency and the use of renewable energy sources are analysed. This allows both to assess the impact of the various targets on the UK energy system in general as well as the industry sector in particular and to explore the interactions between the various target dimensions. In the scenario GHG only the national legislation on GHG emission limits is accounted for, including the four five-yearly carbon budgets that have been fixed so far until 2027 [4] and the long-term target of a $-80 \%$ reduction until 2050 compared to 1990. In order to give the model flexibility with respect to the timing of emission reductions the long-term target is implemented via a cumulative budget constraint which results in the same total amount of emissions as a linear reduction pathway to $-80 \%$ until 2050 would.

The three other low-carbon scenarios also consider the EU regulations on emission reduction in form of the European Emissions Trading System (EU ETS) and the national reduction targets for the nonETS sectors as stipulated in the Effort Sharing Decision [57]. Modelling supranational emission trading schemes in national energy system models such that both the certificate price and the national contribution to emission reduction are reflected correctly is relatively complex [55]. Here a simplified approach both for the ETS and the Non-ETS sector is chosen by setting exogenous carbon prices based on the central projections of the Supplementary Appraisal Guidance on valuing energy use and greenhouse gas emissions from the DECC / HM Treasury Green Book [58]. It is assumed that the sector-specific EU ETS will remain in force until 2030 before it is substituted by a wider emission control system which is reflected in the model by the long-term national target of $-80 \%$. In the EU ETS, certificate prices are projected to stay at a comparatively low level of about $5 £ /$ ton of $\mathrm{CO}_{2}$ eq until 2020 and to rise gradually to $72 £$ /ton of $\mathrm{CO}_{2}$ eq until 2030. For the non-ETS sectors, carbon prices increase from $57 £ /$ ton of $\mathrm{CO}_{2}$ eq in 2015 to $72 £ /$ ton of $\mathrm{CO}_{2}$ eq in 2030 (thus converging with the $\mathrm{EU}$ ETS).

In addition to emission reduction, the EU Climate and Energy Package [9] specified separate targets for energy savings and the use of renewable sources acknowledging their dominant role in emission 
mitigation. In line with these "20-20-20" targets $^{8}$, the UK committed to raise the share of renewable sources in gross final energy consumption to $15 \%$ until 2020 compared to 5\% in 2013 [59] and to cut final energy consumption by $18 \%$ compared to the 2007 business as usual projection for 2020 [60]. Similar EU-wide goals for 2030 were decided in 2014, with a GHG emission reduction of at least $40 \%$, a minimum renewable share of $27 \%$ and an increase in energy efficiency of at least $27 \%$ [10]. No national targets have been fixed for 2030. For this scenario analysis, the 2030 renewable target for the UK has been determined based on the relation between the EU and the UK targets for 2020 resulting in a renewable share in gross final energy consumption of $20.25 \%$. For the reduction in final energy consumption, the EU target of $27 \%$ has been directly applied to the UK. Compared to 2010, this relates to a reduction in final energy consumption (excluding non-energy fuel use) of $8 \%$ until 2020 and of $16 \%$ until 2030.

There is less clarity on the EU-wide targets on renewable energies and energy savings after 2030. In the scenario assumptions, the annual reduction rate in final energy consumption of $0.9 \%$ between 2010 and 2030 is extrapolated until 2050 leading to a fall in the UK's final consumption of $30 \%$ until 2050. Moreover, a minimum renewable share of $50 \%$ is assumed for 2050 which implies a comparatively conservative target level [61] $]^{9}$. In the three low-carbon scenarios reflecting EU energy and climate policy, GHG_EE, GHG_RE and GHG_RE+EE, different combinations of the energy efficiency and renewable targets for the UK are included.

\section{Results of the comparative scenario analysis}

\subsection{Overall energy consumption in the industry sector}

First of all, the development of total final energy consumption in the UK industry sector under the different scenario assumptions is given in Figure 3. In 2010, industrial energy demand is dominated by natural gas (36\%) and electricity $(27 \%)$ and is responsible for about $20 \%$ of total final energy demand. Already in the base case industrial energy consumptions drops by almost a quarter (315 PJ) between 2010 and 2050. This can be attributed to the expected decline in production (responsible for about $12 \%$ of the reduction, cf. Error! Reference source not found.), the shift to high-value, less energy-intensive subsectors, and as some of the modelled energy efficiency measures become cost efficient in the base case due to the rise in fossil fuel prices.

When implementing the $80 \%$ GHG reduction target, total final energy consumption in the UK industry sector remains at about the same level as in the base case over the projected period. Here, two opposing trends need to be taken into account. On the one hand, a stronger emphasis is put on energy efficiency measures, especially in the paper industry and by using more efficient boilers in the less energy-intensive subsectors. On the other hand, the use of CCS technologies in the iron and steel, cement and chemicals industries from 2030 onwards raises the energy demand in these sectors compared to the base case. Natural gas remains the dominant fuel for the provision of low temperature

8 On the European level, the targets are: (1) a reduction of GHG emission of 20\% compared to 1990; (2) a renewable share of $20 \%$ in gross final energy consumption and (3) a reduction of energy consumption of $20 \%$ compared to a previously specified baseline.

9 No upper limit is put on the share of intermittent renewables in electricity generation. A variety of studies have shown that renewable shares of up to $80 \%$ would be technically feasible ([66], [67] for the UK, [68] for the European Union) - and even at manageable cost. While the necessary back-up capacity for intermittent renewables is accounted for in UKTM, it has to be noted that other system effects and costs (in terms of required storage capacity, grid expansion and demand response) are not fully reflected in such a comprehensive energy system model. 
heat. Moreover, a small amount of hydrogen is used in boilers from 2045 onwards which is produced from natural gas reforming and biomass gasification in centralized dedicated plants with CCS.

The comparative scenario analysis shows that in the industry sector the influence of the additional EU targets on renewable sources and energy efficiency only becomes visible after 2030 . While in the scenario GHG the industrial demand for biomass remains on almost the same low level as in the base case, in GHG_RE biomass contributes with 210 PJ (22\%) to industrial energy consumption (mainly for the provision of low-temperature heat) in 2050 which is almost three times more than in GHG. Furthermore, the implementation of the renewable target also leads to a considerable increase in industrial electricity use due to the substantial contribution of electricity generation to the renewable share (further discussed in Chapter 5.4).

The implementation of the energy efficiency target (scenario GHG_EE) only triggers significant additional energy savings in the industry sector after 2040 highlighting that further efficiency efforts in the industry sector are quite costly. The $10 \%$ decrease in final energy demand in the scenario GHG_EE compared to GHG in 2050 can be mainly explained by the reduced use of CCS technologies in the chemicals and cement industries. The scenario results also show that no hydrogen is used in the industry sector when the efficiency or the renewable target is implemented. This is due to the fact that the low-carbon generation of hydrogen with CCS is no longer needed as mitigation option because of the additional efforts in terms of energy efficiency or renewable energies.

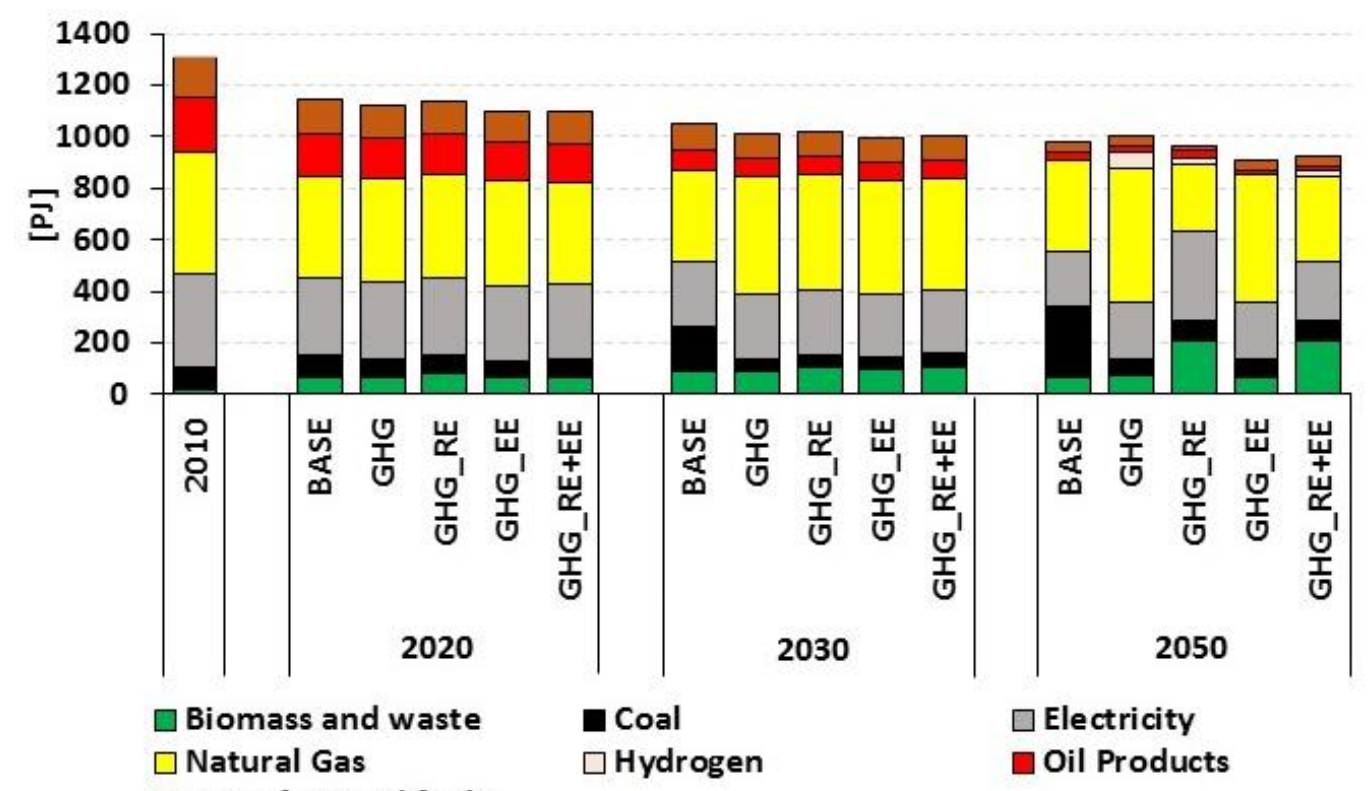

Figure 3: Final energy consumption in the UK industry sector

The scenario GHG_RE+EE, which complies both with the renewable and the energy efficiency target, exhibits a combination of the effects observed for the industry sector in GHG_RE and GHG_EE with an increased use of biomass and limited deployment of CCS. Due to the competition with centralized zero-carbon electricity generation options and the limited availability of bioenergy, a general downward trend in the use of industrial CHP plants can be observed in all GHG scenarios after 2020 with a slightly higher contribution in the scenarios where the efficiency target is implemented. ${ }^{10}$

10 Please note that several sensitivity analyses have been conducted on key input assumptions in UKTM (most importantly on the availability of low-carbon electricity options, biomass resources, fossil fuel prices, tech- 


\subsection{Technology trends in the most energy-intensive industrial subsectors}

353 The main added value of the new industrial modelling approach is the increased process-level detail in the most energy-intensive subsectors. The representation of individual technologies and production routes provides more clarity on how substantial transition pathways can actually be achieved and allows to analyse the interaction between different mitigation options (e.g. fuel switching vs. efficiency improvements vs. CCS). To highlight the additional insights that this new modelling approach can deliver, the final energy consumption for those sectors which are modelled in a process-oriented manner in UKTM is shown in Figure 4. In addition, detailed figures on the technology evolution for the most important production steps in these sectors under the different scenario assumptions can be found in the Annex (see Figure A-1 to A-5).

About three quarters of the steel production in the UK is currently produced through the coke oven blast furnace route, while the remaining share relies on the substantially less energy and emission intensive electric arc furnace route. The expansion of the latter option is, however, constrained in the model due to the limited availability of metal scrap. Because of the comparatively long technology lifetimes and the current overcapacities in the UK steel industry, hardly any differences in the sector's final energy consumption can be observed between the scenarios in the mid-term. After 2030, a shift to more efficient blast furnaces (top-gas recovery and HIsarna steelmaking processes) is cost efficient both in the base case and the low carbon scenarios, with the difference that in the GHG scenarios the CCS variants of these production processes are installed. In the iron \& steel sector, CCS capacities are less affected by the implementation of the energy efficiency target than in other energy-intensive subsectors. With respect to the electric arc furnace route, a shift to Comelt furnaces occurs in all lowcarbon scenarios. Other new production technologies, like the ULCORED or MIDREX direct reduced iron route, do not become competitive. In general, the technology choices are quite similar under the different scenario settings (Figure A-1). Differences in the fuel use occur with respect to boilers: while hydrogen boilers are used after 2040 in the central GHG scenario, they are displaced by natural and blast furnace gas in the scenario GHG_EE (as hydrogen production with CCS is no longer required as mitigation option) and by biomass when the renewable target is implemented.

In the UK cement industry both semi-wet, semi-dry and dry kilns are currently in use. The first two types will be gradually substituted by the more efficient dry kilns in the future. Apart from coal, large amounts of industrial waste are used in these kilns. The use of precalciners as well as the option to reduce the amount of clinker required per unit of cement by substituting for other materials will be extended considerably under all scenario settings. From 2025 onwards, the more energy efficient fluidised bed kilns become competitive in all scenarios and are deployed with increased waste utilisation in the scenarios with the renewable target. In contrast to the iron and steel industry, the long-term development of the cement sector is strongly influenced by the implementation of the energy efficiency target (Figure A-2), showing the completely different dynamics of these sectors, which can only be

nology cost, etc.). Unfortunately, these additional analyses cannot be discussed in detail here. To summarize, the industry sector reacts relatively sensitive to the electricity price (if relevant low-carbon electricity options like nuclear and CCS are removed) switching to a higher use of biomass and even stronger efforts in terms of energy efficiency. Constraints on biomass availability only play a crucial role in the scenarios with renewable target (putting an even stronger weight on renewable electricity generation). The hydrogen use in the industry sector depends strongly on the availability and cost of hydrogen production in centralized CCS plants, while the removal of CCS in industry leads to a higher trend to electrification. The industry sector is also relatively sensitive to the gas price, leading to a stronger use of biomass and electricity in cases with high fossil fuel prices. Comparatively small changes occur when technology costs are increased, given the scale of the decarbonisation challenge. 
analysed by using a process-oriented approach. While heavy reliance is put on kilns with CCS in the scenarios GHG and GHG_RE, carbon capture disappears almost completely in the scenarios complying with the efficiency target. As an alternative mitigation option UKTM contains a "low- $\mathrm{CO}_{2}$ " cement production process representing technologies like Novacem, E-Crete, Celitement or Aether. Due to the high uncertainty of these technologies, relatively high cost assumptions are laid down and their share in total cement production is limited to $20 \%$ in 2050 . Nevertheless, in order to fulfil the target on final energy consumption, this low-carbon option is exploited in the scenarios GHG_EE and GHG_RE+EE.

For the paper industry, the modelling approach concentrates mainly on improvement options for the existing production technologies. While none of these efficiency options are applied in the base case, a strong increase in energy efficiency in paper production is realized in all low-carbon scenarios. The most prominent efficiency options include online moisture management, the switch to impulse drying, as well as several improvements to the press section. With the efficiency target in place, a gradual shift to the alternative production route dry sheet forming also occurs after 2030 (Figure A-3). Due to the large demand for low temperature heat, the paper industry takes a prominent role in the use of biomass when the renewable target is introduced. The equally high biomass demand in the base case can be explained by the availability of low-cost bioenergy resources (which come directly from the paper production and recycling processes) for which in all the low-carbon scenarios the paper industry has to compete with alternative, potentially more valuable usage options (especially in combination with CCS). Similar to the iron and steel industry, hydrogen boilers are deployed after 2040 in the central GHG case, but disappear in the other low-carbon scenarios as the mitigation option of using of low-carbon hydrogen (produced in centralized CCS plants) is replaced by the additional efforts in terms of energy efficiency and/or renewable energy use. 

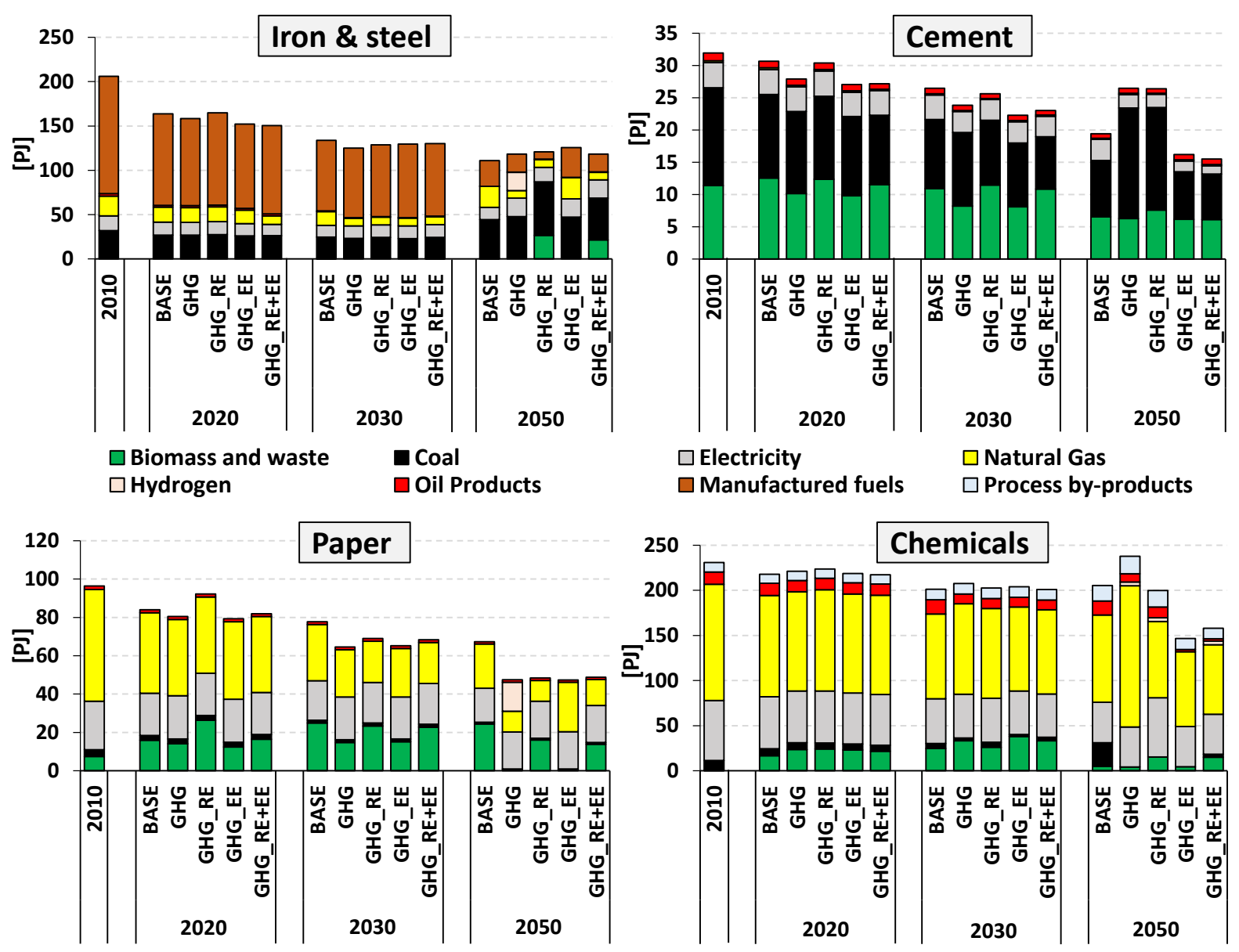

411

Figure 4: Final energy consumption in the energy-intensive industrial subsectors in UKTM

In the chemicals industry, the production of high value chemicals (olefins) and of ammonia are modelled in a process-oriented manner. In both of these sectors, emission mitigation is mainly achieved via CCS options if no additional requirements in terms of energy efficiency are made. Otherwise, a switch to the highly efficient autothermal steam reforming in ammonia production can be observed (Figure A-4). Radical process changes in steam cracking are only realized after 2040 with a limited uptake of Fischer-Tropsch steam crackers in the scenarios GHG_EE and GHG_RE+EE (Figure A-5).

\subsection{The industry sector's contribution to emission reduction}

When looking at emission mitigation, the first relevant insight is that, based on the cumulative budget fixed for 2028 to 2050, in none of the low-carbon scenarios are overall GHG emissions reduced by $80 \%$ in 2050 compared to 1990 (maximum of $-74 \%$ in the scenario GHG_EE). With the cumulative approach, early action is favoured such that especially between 2030 and 2040 higher emission cuts are realised than a linear reduction path would imply thereby avoiding investments in additional, costly abatement options in 2050 .

As expected, emission mitigation is dominated by the electricity sector where in the scenarios GHG and GHG_EE even negative emissions are achieved after 2030 through the use of biomass CCS plants $^{11}$ (Figure 5). The implementation of the renewable target increases the competition for the scarce biomass resources leading to a shift to wind and (to a much smaller extent) solar energy and a

11 Biomass resources are assumed to be carbon-neutral in the model following the bioenergy emission accounting approach of the EU Renewable Energy Directive [63]. 
slightly higher emission level in electricity generation in 2050. In relative terms (lower part of Figure 5), the industry sector reaches the second highest GHG emission reduction between 2010 and 2050 across sectors in those scenarios where the energy efficiency target is not implemented (up to -77\%). As mentioned before, the constraint on total final energy consumption leads to a lower deployment of industrial CCS plants while at the same time emission mitigation in the residential and transport sectors is raised. In absolute terms (upper part of Figure 5), the industry sector takes a less prominent role with the emission reduction in 2050 of $-50 \mathrm{Mt} \mathrm{CO}_{2} \mathrm{eq}$ in the scenario GHG. The absolute emission reduction figures also reveal the negative emissions generated in hydrogen production through the use of biomass CCS in 2050.

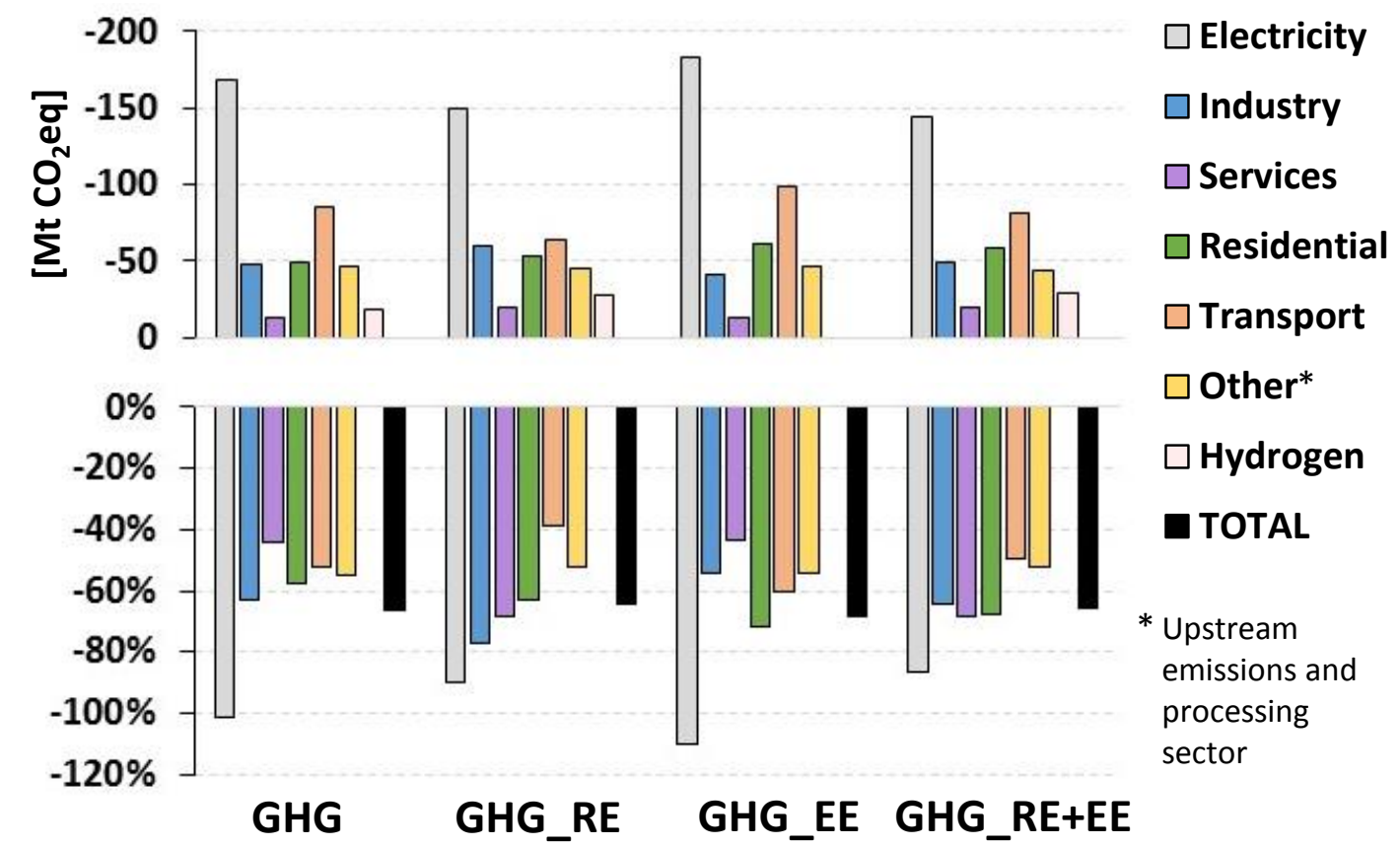

Figure 5: Absolute (top) and relative (bottom) GHG emission reduction between 2010 and 2050 by sector

With respect to emission mitigation, the strength of the new process-oriented modelling approach can be identified in the addition of crucial mitigation options, especially to the energy-intensive subsectors. This increases the confidence in the actual feasibility of these mitigation pathways. Also, when comparing the results at hand with previous energy system analyses with UK MARKAL, it becomes evident that the contribution of the industry sector to decarbonisation has clearly increased [62] ${ }^{12}$.

\subsection{The industry sector's contribution to renewable targets}

The EU target on the minimum share of renewable sources in gross final energy consumption can be complied with in three different ways: (1) raising the contribution of renewables to electricity generation; (2) increasing the share of biofuels in the transport sector and (3) extending the direct use of bioenergy and other renewable sources for heating and cooling in the residential, services and industry sector (Table ). With the new process-oriented modelling approach, additional deployment options for biomass are represented in the industry sector, most importantly kilns with biomass and waste utilization in the cement sector, steam crackers in the chemicals industry and industrial CHP plants (both for solid biomass and biogas).

12 For scenarios with a $-80 \% \mathrm{CO}_{2}$ reduction target, the analyses with UK MARKAL in [62] yielded changes in industrial final energy demand ranging from $-10 \%$ to $+5 \%$ and industrial $\mathrm{CO}_{2}$ reductions ranging from $21 \%$ to $58 \%$ by 2050 compared to 2010 . 
The scenario analysis at hand shows that renewable electricity generation will play a dominant role in fulfilling the renewable target. In the scenarios GHG_RE and GHG_RE+EE a rapid increase in the renewable share in electricity production from $7.4 \%$ in 2010 to up to $73 \%$ in 2050 is realized, mainly based on onshore and offshore wind energy. Shares of intermittent sources in electricity generation of up to $66 \%$ will have substantial impacts on the electricity system. In UKTM, this is reflected in the significant amount of back-up capacity required in the scenarios with renewable target (more than $50 \mathrm{GW}$ of open cycle gas turbines in 2050 run at very low capacity factors).

In the two low-carbon scenarios without minimum renewable requirements much more reliance is put on nuclear energy. Only in the mid-term where the expansion of nuclear plants is restricted by the imposed growth constraints, renewable sources (mainly biomass CCS) cover up to half of total electricity generation in these scenarios. From 2040 onwards, hydrogen generation is one of the major consumers of biomass in the scenarios GHG_RE and GHG_RE+EE even though the contribution of hydrogen to total final energy demand remains rather limited in these scenarios (4\% in 2050).

The increased deployment of biofuels in the transport sector in 2020 in the scenarios where the renewable target is implemented can be attributed to the sub-target for the transport sector of the EU Renewable Directive of $10 \%$ (with multiplication factors for certain biofuels [63]). Assuming that this additional transport target is discontinued after 2020, the scenario analysis shows that due to the limited availability of bioenergy resources, the use of biofuels in transport is not a cost-efficient option to comply with the renewable target. However, both the renewable and the efficiency target lead to a stronger use of electricity in the transport sector at the expense of hydrogen.

Table 3: Contribution to the renewable target by sector

\begin{tabular}{|c|c|c|c|c|c|c|c|c|c|c|c|c|}
\hline & \multicolumn{4}{|c|}{2020} & \multicolumn{4}{|c|}{2030} & \multicolumn{4}{|c|}{2050} \\
\hline & GHG & $\begin{array}{c}\mathrm{GHG}_{-} \\
\mathrm{RE}\end{array}$ & $\underset{\mathrm{EE}}{\mathrm{GHG}_{-}}$ & $\begin{array}{l}\text { GHG_- } \\
\text { RE+EE }\end{array}$ & GHG & $\begin{array}{c}\mathrm{GHG}_{-} \\
\mathrm{RE}\end{array}$ & $\begin{array}{c}\mathrm{GHG}_{\mathrm{EE}} \\
\end{array}$ & $\begin{array}{l}\mathrm{GHG}_{-} \\
\mathrm{RE}+\mathrm{EE}\end{array}$ & GHG & $\begin{array}{c}\mathrm{GHG}_{-} \\
\mathrm{RE}\end{array}$ & $\begin{array}{c}\mathrm{GHG}_{\mathrm{EE}} \\
\mathrm{E}\end{array}$ & $\begin{array}{l}\text { GHG } \\
\text { RE+EE }\end{array}$ \\
\hline RE share in electricity & $15 \%$ & $36 \%$ & $12 \%$ & $41 \%$ & $53 \%$ & $58 \%$ & $52 \%$ & $58 \%$ & $19 \%$ & $73 \%$ & $20 \%$ & $68 \%$ \\
\hline RE share in hydrogen & $0 \%$ & $0 \%$ & $5 \%$ & $0 \%$ & $3 \%$ & $84 \%$ & $6 \%$ & $83 \%$ & $21 \%$ & $99 \%$ & $7 \%$ & $99 \%$ \\
\hline RE share in transport & $1 \%$ & $7 \%$ & $1 \%$ & $7 \%$ & $2 \%$ & $6 \%$ & $2 \%$ & $6 \%$ & $0 \%$ & $0 \%$ & $0 \%$ & $0 \%$ \\
\hline $\begin{array}{l}\text { RE share in heating and } \\
\text { cooling }\end{array}$ & $4 \%$ & $13 \%$ & $4 \%$ & $11 \%$ & $7 \%$ & $14 \%$ & $7 \%$ & $13 \%$ & $30 \%$ & $50 \%$ & $29 \%$ & $56 \%$ \\
\hline Industry & $7 \%$ & $10 \%$ & $7 \%$ & $10 \%$ & $12 \%$ & $14 \%$ & $13 \%$ & $14 \%$ & $11 \%$ & $42 \%$ & $10 \%$ & $38 \%$ \\
\hline Residential & $1 \%$ & $4 \%$ & $1 \%$ & $2 \%$ & $2 \%$ & $7 \%$ & $3 \%$ & $4 \%$ & $43 \%$ & $54 \%$ & $51 \%$ & $67 \%$ \\
\hline Services \& agriculture & $7 \%$ & $43 \%$ & $7 \%$ & $41 \%$ & $16 \%$ & $33 \%$ & $10 \%$ & $39 \%$ & $32 \%$ & $48 \%$ & $8 \%$ & $49 \%$ \\
\hline Overall RE share & $5 \%$ & $15 \%$ & $4 \%$ & $15 \%$ & $14 \%$ & $20 \%$ & $15 \%$ & $20 \%$ & $20 \%$ & $50 \%$ & $19 \%$ & $50 \%$ \\
\hline Total RE consumption [PJ] & 262 & 839 & 229 & 843 & 760 & 1057 & 744 & 1066 & 1073 & 1934 & 944 & 2061 \\
\hline
\end{tabular}

For heating and cooling, the share of renewable sources directly used for these services in total final energy demand of the agriculture, services, industrial and residential sectors (without electricity consumption) is calculated. The scenario results indicate that in the heating sector the expansion of renewable energies is delayed when compared with electricity generation. In 2020, substantial differences between the scenarios with and without the minimum renewable requirements can only be observed in the services and agricultural sectors, where the deployment of biomass boilers rises considerably. In the residential sector, a significant contribution to the renewable target is only visible after 2030 with a massive roll-out of electric heat pumps. With up to $42 \%$ of total energy demand for heating in 2050, the renewable share in the industrial sector is lower than in the residential and services sector. However, the industry sector is the second largest consumer of biomass (after hydrogen gener- 
ation) in the long term. It has to be noted that under the assumed technology parameters, the use of biomass in industrial CHP plants remains comparatively limited, competing with centralized biomass CCS plants in hydrogen and electricity generation.

Comparing the overall renewable shares between the scenarios with and without minimum requirements for renewable sources (50\% vs. $20 \%$ in 2050) shows that under the chosen scenario assumptions, an ambitious expansion of renewable energy in the UK is not the most cost-efficient mitigation option.

\subsection{The industry sector's contribution to energy efficiency}

In UKTM, energy savings can be achieved through the deployment of more efficient technologies as well as fuel substitution. In addition, endogenous energy service demand reductions due to changes in the prices for these services are taken into account by applying own-price elasticities to the various demand commodities. In the energy-intensive industry sectors, a large variety of both replacement technologies with higher efficiency and improvements to existing production routes (e.g. the use of waste heat) are taken into account with the new modelling approach, while in the less energyintensive sectors efficiency can mainly be improved through the use of high efficiency boilers.

In the base case, total final energy consumption remains at about today's level over the observed period (Figure 6). Industry is the only sector whose energy consumption drops considerably until 2050 without the implementation of emission targets. Strong increases in energy demand occur especially in the transport sector. When the long-term GHG reduction target for the UK is taken into consideration (scenario GHG), increasing energy efficiency is one of the main abatement strategies with a decline in final energy demand of $23 \%$ until 2050 . While, as mentioned before, no further reductions compared to the base case are realized in the industry sector, significant efforts are undertaken in the residential sector through the uptake of conservation measures as well as a trend to electrification. In the transport sector, which exhibits the highest reduction rate between 2010 and 2050, efficiency is initially increased by the use of hybrid electric vehicles which after 2030 are partly replaced by electric (mainly cars and light-duty transport) and hydrogen (mainly heavy-duty transport) vehicles. The lowering effect of conservation measures applied in the services sector is, in the long term, more than offset by the sector's rising energy services demand caused by a still growing share in gross value added and the associated increase in commercial floor space.

The results for the scenario GHG_RE show that a simultaneous increase in energy efficiency is used as one strategy to comply with the renewable target in the long-term. Especially in the transport sector additional reductions in final energy demand are achieved through a stronger electrification.

When introducing the additional target on energy efficiency, additional energy savings compared to the scenario GHG can be observed for all end-use sectors and involve the installation of more efficient technologies, a higher rate of electrification as well as a switch from biomass to highly efficient natural gas boilers. In comparison to the baseline, the strongest changes occur in the transport sector, while in the industry sector the reduction in final energy demand between 2010 and 2050 is only raised from $-24 \%$ in the base case to up to $-31 \%$ in the scenario GHG_EE. Hence, the decline of industrial energy demand plays a crucial role in reaching long-term energy efficiency targets, but most of these reductions are already realized in the absence of any policy targets. 


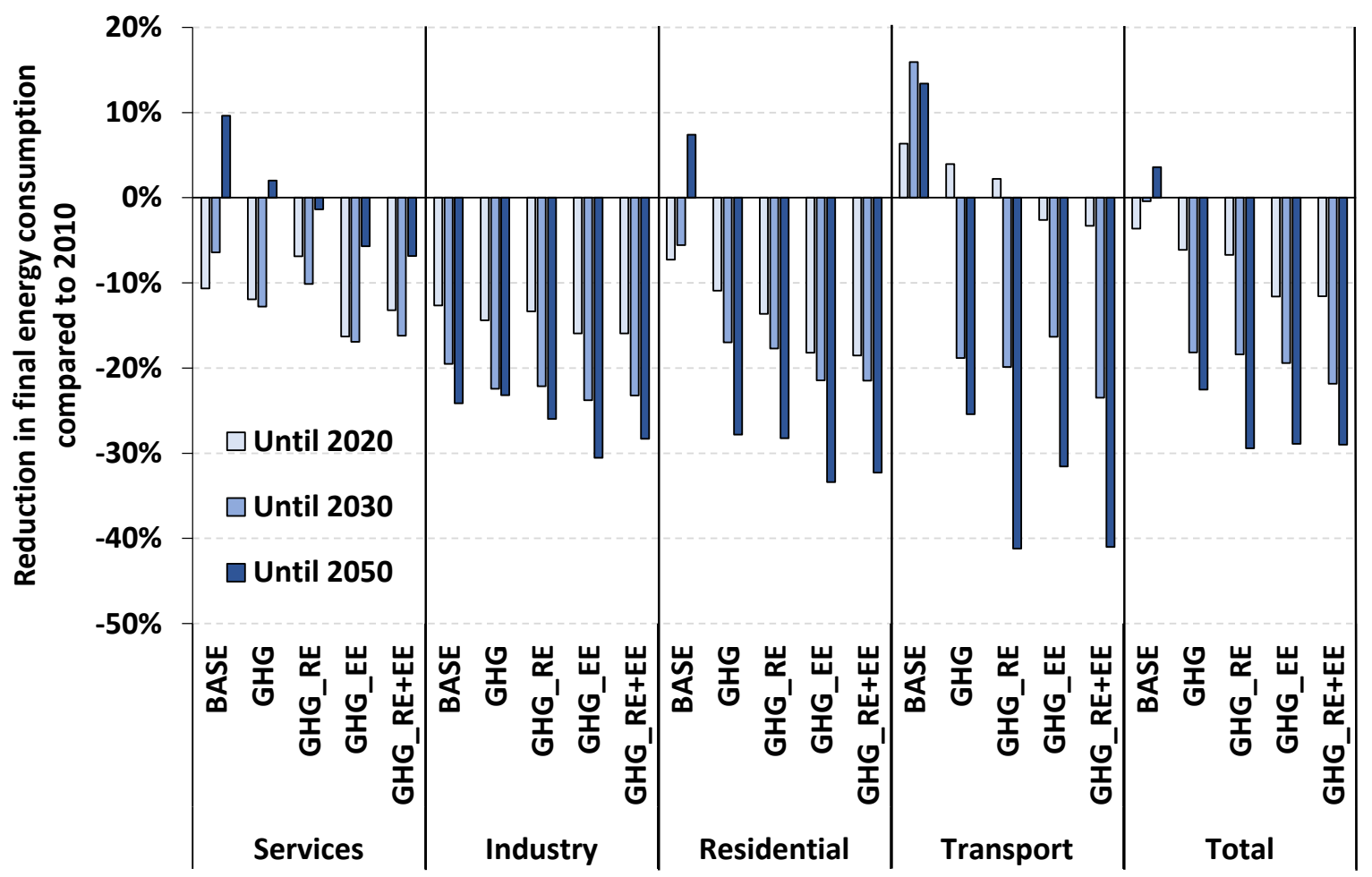

527

Figure 6: Change in final energy consumption by sector compared to 2010

\subsection{Overlapping policy cost impacts}

Apart from technology deployment and fuel use, the UKTM results also allow a comparison of the different scenarios in terms of implications on costs. For each scenario, the least-cost pathway for the long-term development of the UK energy system under the given assumptions is calculated. With the representation of actual technology options and their associated cost parameters in the industry sector, greater reliability of the contribution of the industry sector to overall system costs has been achieved with the new modelling approach.

First, the scenarios are contrasted in terms of the carbon price which is given in the model as the shadow price of the carbon constraint (Figure 7). In the scenario GHG, a first strong increase in the price on GHG emissions to over $100 £ / t \mathrm{CO}_{2}$ eq occurs with the implementation of the $4^{\text {th }}$ Carbon Budget (2023-2027). Afterwards, the formulation of the $-80 \%$ target as a cumulative emission budget covering the period from 2028 to 2050 results in a smoothly increasing carbon price reaching slightly above $400 £ / \mathrm{t} \mathrm{CO}_{2}$ eq in 2050. It has to be pointed out that the carbon price would be significantly higher in 2050 if a linear reduction pathway forcing the model to a $-80 \%$ reduction in 2050 was implemented.

In the scenarios which take the European policy targets into account, the price of carbon is, until 2030, mainly determined by the exogenously set ETS and non-ETS prices. After 2020 the same cumulative target is assumed as in the scenario GHG. It clearly shows that both the renewable and the energy efficiency target have a dampening effect on the carbon price signal. In 2050, the price for GHG emissions ranges between 200 (GHG_RE+EE) and 260 (GHG_RE) $£ / t \mathrm{CO}_{2}$ eq. This does not imply that the mitigation targets are reached in a less costly way in these scenarios as the shadow prices on the renewable and efficiency constraints also need to be taken into consideration, which reach up to $58 £ / G J$ of renewable energy used and up to $84 £ / G J$ of final energy demand reduced. 


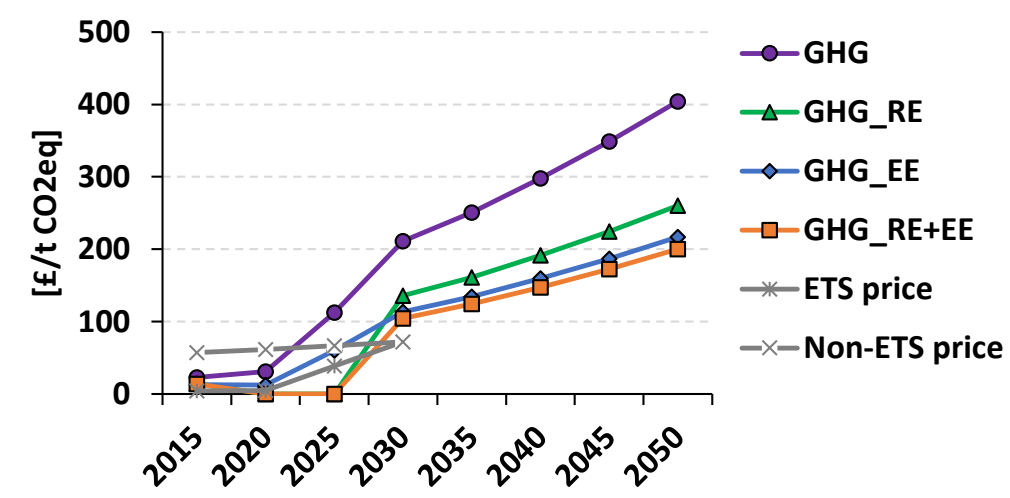

Figure 7: Carbon prices in the scenario analysis

In order to assess the additional system-wide cost burden that is caused by the implementation of the different climate and energy policy targets in a consistent manner a look is taken at total societal welfare costs. These are defined as the net total surplus of producers and consumers and comprise the entire costs of a specific energy system in a certain region and a certain period, covering capital costs for energy conversion and transport technologies, fixed operating and maintenance costs as well as fuel and certificate costs.

The cost burden resulting from the transition to a low-carbon energy system in the UK increases steadily over the projected period with a difference in total annual undiscounted welfare costs of $6 \%$ in 2020 and of $11 \%$ in 2050 between the scenario GHG and the base case (Table ). In absolute terms, the difference amounts to more than $£ 1300$ billion (in real terms) when cumulated over the period from 2010 and 2050. The results also highlight that putting additional constraints on the energy system in terms of minimum requirements for renewable energy or energy efficiency increases the cost reflected in a cumulated cost difference to the scenario GHG of $£ 540$ billion for GHG_RE and of $£ 322$ billion for GHG_EE over the period 2010 to 2050. The fact that this cost difference decreases over time indicates that especially in the mid-term the current EU target levels have a strong influence on the chosen mitigation options associated with substantial additional costs for the energy system.

Table 4: Comparison of annual undiscounted welfare cost

\begin{tabular}{|ll|ccc|c|}
\hline & & $\mathbf{2 0 2 0}$ & $\mathbf{2 0 3 0}$ & $\mathbf{2 0 5 0}$ & $\begin{array}{c}\text { Cumulated } \\
\mathbf{2 0 1 0 - 2 0 5 0}[\mathbf{B n} \text { f] }\end{array}$ \\
\hline GHG & vs. BASE & $6.0 \%$ & $7.4 \%$ & $11.0 \%$ & 1356 \\
\hline \multirow{2}{*}{ GHG_RE } & vs. BASE & $9.5 \%$ & $10.5 \%$ & $13.1 \%$ & 1896 \\
& vs. GHG & $3.3 \%$ & $2.9 \%$ & $1.9 \%$ & 540 \\
\hline \multirow{2}{*}{ GHG_EE } & vs. BASE & $8.9 \%$ & $10.2 \%$ & $10.9 \%$ & 1677 \\
& vs. GHG & $2.8 \%$ & $2.6 \%$ & $-0.1 \%$ & 322 \\
\hline \multirow{2}{*}{ GHG_RE+EE } & vs. $\mathbf{B A S E}$ & $9.6 \%$ & $10.7 \%$ & $13.2 \%$ & 1911 \\
& vs. GHG & $3.4 \%$ & $3.1 \%$ & $2.0 \%$ & 555 \\
\hline
\end{tabular}

\section{Conclusions and Policy Implications}

This paper has introduced a new methodological approach for a more detailed representation of the industrial sector based on an integration of bottom-up process level database, but still contained within a whole energy system modelling framework. Presented here for a case study of the UK, this methodology could be easily transferred to other national settings. 
577 The subsequent quantitative scenario analysis of the UK energy system has shown how this process-

578 oriented representation of the industry sector in an energy system analysis can help to evaluate the

579 contribution of this sector to long-term climate and energy policy targets. The scenario results indicate

580 that the UK's industry sector will have to play a key part in the decarbonisation process, both in terms

581 of its use of low-carbon upstream vectors and in process mitigation options within the subsectors. The

582 industry sector will also be a major contributor to achieving the energy efficiency target, while it plays

583 a slightly less prominent role in the expansion of renewable energies, which is mainly limited to the

584 use of biomass for low-temperature heating services. Ambitious renewable targets will most strongly

585 affect electricity generation where high shares of intermittent sources will have substantial effects on

586 the electricity system in terms of back-up and storage capacity, grid reinforcement and expansion as

587 well as demand-side management. Such system effects are not fully reflected in the scenario analysis

588 with UKTM.

589 The scenario analysis also highlights that the implementation of additional policy targets apart from 590 emission mitigation, as it is being done in the European Union in the case of renewable source and 591 energy efficiency, needs to be examined critically. Such additional targets can distort the cost efficient 592 strategy of reaching the desired emission reductions and lead to additional cost burdens for consum593 ers. Setting additional sub-targets and implementing technology- or sector-specific policy instruments 594 might be justified from a second-best perspective where not all environmental externalities from cli595 mate change are yet internalized and substantial uncertainty about future carbon price signals exists 596 ([64] \& [54]). Moreover, other political motivations for the promotion of renewable sources and ener597 gy efficiency need to be taken into account, as for example a reduction of import dependency, allevia598 tion of fuel poverty or technology promotion in order to realize learning effects. Yet, even if these 599 additional target dimensions can be justified, it is essential to take the interactions between them into 600 account.

601 With respect to the modelling approach, further methodological work will be needed to improve the 602 representation of the less energy-intensive industrial subsectors in bottom-up energy system models. 603 The fact that also from these industry sectors substantial mitigation efforts will be required highlights 604 that targeted policy engagement with these highly heterogeneous sectors, often dominated by small605 and medium-sized companies, will be required. In addition, the significant uncertainties in the cost 606 and efficiency assumptions of future industrial technology options, which often constitute radical pro607 cess changes, need to be addressed thoroughly. However, the methodological advance presented in 608 this paper has shown how a process-oriented representation of the industry sector based on a compre609 hensive technology database can provide a more detailed and consistent picture of the sector's role in 610 long-term energy and climate policy targets within the scope of a whole energy system analysis.

\section{Acknowledgement}

613 This research was supported under the Whole Systems Energy Modelling Consortium (WholeSEM) 614 Ref: EP/K039326/1. 


\section{References}

[1] IPCC, 2014: Summary for Policymakers. In: Climate Change 2014: Mitigation of Climate Change. Contribution of Working Group III to the Fifth Assessment Report of the Intergovernmental Panel on Climate Change [Edenhofer, O., R. Pichs-Madruga, Y. Sokona, E. Farahani, S. Kadner, K. Seyboth, A. Adler, I. Baum, S. Brunner, P. Eickemeier, B. Kriemann, J. Savolainen, S. Schlömer, C. von Stechow, T. Zwickel and J.C. Minx (eds.)]. Cambridge University Press, Cambridge, United Kingdom and New York, NY, USA.

[2] Jaccard, M., Agbenmabiese, L., Azar, C., de Oliveira, A., Fischer, C., Fisher, B., ... Zhang, X. (2012). Chapter 22 - Policies for Energy System Transformations: Objectives and Instruments. In: Global Energy Assessment - Toward a Sustainable Future (pp. 1549-1602). Cambridge University Press, Cambridge, UK and New York, NY, USA and the International Institute for Applied Systems Analysis, Laxenburg, Austria.

[3] DECC (2011). The Carbon Plan: Delivering our low carbon future. London: Department of Energy and Climate Change.

[4] CCC (2013). Fourth Carbon Budget Review - part 2, The cost-effective path to the 2050 target. London: Committee on Climate Change.

[5] Grubb, M. (2014). Planetary Economics: Energy, Climate Change and the Three Domains of Sustainable Development. London, UK, Routledge.

[6] Napp, T.A., Gambhir, A., Hills, T.P., Florin, N., Fennell, P.S. (2014). A review of the technologies, economics and policy instruments for decarbonising energy-intensive manufacturing industries. Renewable and sustainable energy reviews, 30, 616 - 640 . doi: http://dx.doi.org/10.1016/j.rser.2013.10.036

[7] Fischedick M., J. Roy, A. Abdel-Aziz, A. Acquaye, J. M. Allwood, J.-P. Ceron, Y. Geng, H. Kheshgi, A. Lanza, D. Perczyk, L. Price, E. Santalla, C. Sheinbaum, and K. Tanaka, 2014: Industry. In: Climate Change 2014: Mitigation of Climate Change. Contribution of Working Group III to the Fifth Assessment Report of the Intergovernmental Panel on Climate Change [Edenhofer, O., R. Pichs-Madruga, Y. Sokona, E. Farahani, S. Kadner, K. Seyboth, A. Adler, I. Baum, S. Brunner, P. Eickemeier, B. Kriemann, J. Savolainen, S. Schlömer, C. von Stechow, T. Zwickel and J.C. Minx (eds.)]. Cambridge University Press, Cambridge, United Kingdom and New York, NY, USA.

[8] Parsons Brinckerhoff and DNV GL (2015). Industrial Decarbonisation \& Energy Efficiency Roadmaps to 2050, Cross-sector Summary. Report for the Department of Energy and Climate Change and the Department for Business, Innovation and Skills.

[9] European Commission (EC) (2008). Communication from the Commission to the European Parliament, the Council, the European Economic and Social Committee and the Committee of the Regions - 2020 by 2020 - Europe's climate change opportunity \{COM(2008) 30 final\}. Brussels: European Commission (EC).

[10] European Commission (EC) (2014). Communication from the Commission to the European Parliament, the Council, the European Economic and Social Committee and the Committee of the Regions: A policy framework for climate and energy in the period from 2020 to 2030 \{COM(2014) 15 final $\}$. Brussels: European Commission (EC).

[11] Karali, N., Xu, T., \& Sathaye, J. (2012). Industrial Sector Energy Efficiency Modeling (ISEEM) Framework Documentation. LBNL Final Report. Berkeley: Lawrence Berkeley National Laboratory.

[12] Kannan, R., \& Strachan, N. (2009). Modelling the UK residential energy sector under longterm decarbonisation scenarios: Comparison between energy systems and sectoral modelling approaches. Applied Energy, 86(4), 416-428. doi: http://dx.doi.org/10.1016/j.apenergy.2008.08. $\underline{005}$ 
[13] Swan, L. G., \& Ugursal, V. I. (2009). Modeling of end-use energy consumption in the residential sector: A review of modeling techniques. Renewable and Sustainable Energy Reviews, 13(8), 1819-1835. doi: http://dx.doi.org/10.1016/j.rser.2008.09.033

[14] Wilkerson, J. T., Cullenward, D., Davidian, D., \& Weyant, J. P. (2013). End use technology choice in the National Energy Modeling System (NEMS): An analysis of the residential and commercial building sectors. Energy Economics, 40(0), 773-784. doi: http://dx.doi.org/10.1016/j.eneco.2013.09.023

[15] Dodds, P. E., \& McDowall, W. (2014). Methodologies for representing the road transport sector in energy system models. International Journal of Hydrogen Energy, 39(5), 2345-2358. doi: http://dx.doi.org/10.1016/j.ijhydene.2013.11.021

[16] Daly, H. E., Ramea, K., Chiodi, A., Yeh, S., Gargiulo, M., \& Gallachóir, B. Ó. (2014). Incorporating travel behaviour and travel time into TIMES energy system models. Applied Energy, 135(0), 429-439. doi: http://dx.doi.org/10.1016/j.apenergy.2014.08.051

[17] Anable, J., Brand, C., Tran, M., \& Eyre, N. (2012). Modelling transport energy demand: A socio-technical approach. Energy Policy, 41(0), 125-138. doi: http://dx.doi.org/10.1016/j.enpol.2010.08.020

[18] Fleiter, T., Fehrenbach, D., Worrell, E., \& Eichhammer, W. (2012). Energy efficiency in the German pulp and paper industry - A model-based assessment of saving potentials. Energy, 40(1), 84-99. doi: 10.1016/j.energy.2012.02.025

[19] Hasanbeigi, A., Morrow, W., Masanet, E., Sathaye, J., \& Xu, T. (2013). Energy efficiency improvement and $\mathrm{CO} 2$ emission reduction opportunities in the cement industry in China. Energy Policy, 57, 287-297. doi: 10.1016/j.enpol.2013.01.053

[20] Pardo, N., \& Moya, J. A. (2013). Prospective scenarios on energy efficiency and $\mathrm{CO}_{2}$ emissions in the European Iron \& Steel industry. Energy, 54, 113-128. doi: 10.1016/j.energy.2013.03.015

[21] Porzio, G. F., Fornai, B., Amato, A., Matarese, N., Vannucci, M., Chiappelli, L., \& Colla, V. (2013). Reducing the energy consumption and $\mathrm{CO}_{2}$ emissions of energy intensive industries through decision support systems - An example of application to the steel industry. Applied Energy, 112, 818-833. doi: 10.1016/j.apenergy.2013.05.005

[22] Broeren, M. L. M., Saygin, D., \& Patel, M. K. (2014). Forecasting global developments in the basic chemical industry for environmental policy analysis. Energy Policy, 64, 273-287. doi: 10.1016/j.enpol.2013.09.025

[23] Brunke, J.-C., \& Blesl, M. (2014). A plant-specific bottom-up approach for assessing the costeffective energy conservation potential and its ability to compensate rising energy-related costs in the German iron and steel industry. Energy Policy, 67, 431-446. doi: 10.1016/j.enpol.2013.12.024

[24] Karali, N., Xu, T., \& Sathaye, J. (2014). Reducing energy consumption and $\mathrm{CO}_{2}$ emissions by energy efficiency measures and international trading: A bottom-up modeling for the U.S. iron and steel sector. Applied Energy, 120, 133-146. doi: 10.1016/j.apenergy.2014.01.055

[25] Kannan, R., Strachan, N., Pye, S. Anandarajah, G., \& Balta-Ozkan, N. (2007). UK MARKAL Model Documentation. Retrieved from the UCL Energy Institute Models website: www.ucl.ac.uk/energy-models/models/uk-markal

[26] Loulou, R., \& Labriet, M. (2008). ETSAP-TIAM: the TIMES integrated assessment model Part I: Model structure. Computational Management Science, 5(1-2), 7-40. doi: 10.1007/s10287007-0046-z

[27] E3MLab (2014). PRIMES Model 2013-2014, Detailed model description. Retrieved from the E3MLab / ICCS website, National Technical University of Athens: www.e3mlab.ntua.gr/e3mlab/PRIMES\% 20Manual/The\%20PRIMES\%20MODEL\%2020132014.pdf 
[28] U.S. Energy Information Administration (EIA) (2013). Model Documentation Report: Industrial Demand Module of the National Energy Modeling System. Retrieved from the EIA website: www.eia. gov/forecasts/aeo/nems/documentation/industrial/pdf/m064\%282013\%29.pdf

[29] International Energy Agency (IEA) (2014). Energy Technology Perspectives 2014 - Harnessing Electricity's Potential. Paris: Organisation for Economic Co-operation and Development (OECD) / International Energy Agency (IEA).

[30] Simoes, S., Nijs, W., Ruiz, P., Sgobbi, A., Radu, D., Bolat, P., Thiel, Ch., \& Peteves, S. (2013). The JRC-EU-TIMES model. JRC Scientific and Policy Reports. Petten: European Commission Joint Research Centre. doi: 10.2790/97596

[31] Wiedmann, T. (2009). A review of recent multi-region input-output models used for consumption-based emission and resource accounting. Ecological Economics, 69(2), 211-222. doi: http://dx.doi.org/10.1016/j.ecolecon.2009.08.026

[32] Tukker, A., \& Dietzenbacher, E. (2013). Global Multiregional Input-Output Frameworks: an Introduction and Outlook. Economic Systems Research, 25(1), 1-19. doi: 10.1080/09535314.2012.761179

[33] Barrett, J., Peters, G., Wiedmann, T., Scott, K., Lenzen, M., Roelich, K., \& Le Quéré, C. (2013). Consumption-based GHG emission accounting: a UK case study. Climate Policy, 13(4), 451-470. doi: 10.1080/14693062.2013.788858

[34] Böhringer, C., Balistreri, E. J., \& Rutherford, T. F. (2012). The role of border carbon adjustment in unilateral climate policy: Overview of an Energy Modeling Forum study (EMF 29). Energy Economics, 34, Supplement 2(0), S97-S110. doi: http://dx.doi.org/10.1016/j.eneco.2012.10.003

[35] Guo, Z., Zhang, X., Zheng, Y., \& Rao, R. (2014). Exploring the impacts of a carbon tax on the Chinese economy using a CGE model with a detailed disaggregation of energy sectors. Energy Economics, 45(0), 455-462. doi: http://dx.doi.org/10.1016/j.eneco.2014.08.016

[36] Fujimori, S., Kainuma, M., Masui, T., Hasegawa, T., \& Dai, H. (2014). The effectiveness of energy service demand reduction: A scenario analysis of global climate change mitigation. Energy Policy, 75(0), 379-391. doi: http://dx.doi.org/10.1016/j.enpol.2014.09.015

[37] Loulou, R., Remme, U., Lehtilä, A., Kanudia, A., \& Goldstein, G. (2005). Documentation for the TIMES model. Retrieved from the Energy Technology Systems Analysis Program (ETSAP) website: http://www.iea-etsap.org/web/Documentation.asp

[38] Ekins, P., Anandarajah, G., \& Strachan, N. (2011). Towards a low-carbon economy: scenarios and policies for the UK. Climate Policy, 11(2), 865-882. doi: 10.3763/cpol.2010.0126

[39] DTI (2007). Energy White Paper: Meeting the Energy Challenge. London: Department of Trade and Industry.

[40] CCC (2008). Building a low-carbon economy - the UK's contribution to tackling climate change. London: Committee on Climate Change.

[41] Daly, H. E., Scott, K., Strachan, N., \& Barrett, J. R. (2015). The indirect $\mathrm{CO}_{2}$ emission implications of energy system pathways: Linking IO and TIMES models for the UK. Environmental Science \& Technology. doi: 10.1021/acs.est.5b01020

[42] Dodds, P., Daly, H., \& Fais, B. (2014). Benefits of incorporating non-energy and non- $\mathrm{CO}_{2}$ processes into energy systems models. Conference paper for the $14^{\text {th }}$ IAEE European Energy Conference, Rome, 28-31 October 2014.

[43] Daly, H. E., Dodds, P. E., \& Fais, B. (2015). UK TIMES Model Documentation, version 1.0. London: UCL Energy Institute. (Forthcoming)

[44] Griffin, P., Hammond, G., \& Norman, J. (2013). Industrial Energy Use from a Bottom-Up Perspective: Developing the Usable Energy Database (Beta version). UK Energy Research Centre 
(UKERC/WP/ED/2013/002). Retrieved from the UKERC website: http://data.ukedc.rl.ac.uk/ browse/edc/EnergyConsumption/Industry/UED_Documentation.pdf

[45] DECC (2012). Energy Consumption in the UK (2012) Statistics. London: Department of Energy and Climate Change.

[46] OBR (2012). Fiscal sustainability report, July 2012. London: Office for Budget Responsibility.

[47] ONS (2011). National Population Projections, 2010-based. Newport: Office for National Statistics.

[48] Anandarajah, G., Pye, S., Usher, W., Kesicki, F., \& McGlade, Ch. (2011). TIAM-UCL Global Model Documentation. UK Energy Research Centre Working Paper (UKERC/WP/ESY/2011/001). Retrieved from the UCL Energy Institute Models website: http://www.ucl.ac.uk/energy-models/models/tiam-ucl/tiam-ucl-manual

[49] CCC (2011). Bioenergy Review. London: Committee on Climate Change.

[50] HM Treasury (2011). The Green Book. London: HM Treasury.

[51] Strachan, N., \& Usher, W. (2010). UK MARKAL Modelling - Examining Decarbonisation Pathways in the 2020s on the Way to Meeting the 2050 Emissions Target (Final Report for the Committee on Climate Change). Retrieved from the UCL Energy Institute website: http://www.ucl.ac.uk/energy-models/models/uk-markal/ccc-fourth-carbon-budget-final-reportuk-markal-updates

[52] CCC (2011). Time preference, costs of capital and hidden costs: a Committee on Climate Change Note. Retrieved from the CCC website: http://archive.theccc.org.uk laws/Time $\% 20$ prefernce, $\% 20$ costs $\% 20$ of $\% 20$ capital $\% 20$ and $\% 20$ hiddencosts.pdf

[53] Pye, S., Usher, W., \& Strachan, N. (2014). The uncertain but critical role of demand reduction in meeting long-term energy decarbonisation targets. Energy Policy, 73, 575-586. doi: 10.1016/j.enpol.2014.05.025

[54] Bennear, L., \& Stavins, R. (2007). Second-best theory and the use of multiple policy instruments. Environmental and Resource Economics, 37(1), 111-129. doi: 10.1007/s10640-0079110-y

[55] Fais, B., Blesl, M., Fahl, U., \& Voß, A. (2014). Analysing the interaction between emission trading and renewable electricity support in TIMES. Climate Policy. doi: $10.1080 / 14693062.2014 .927749$

[56] Anandarajah, G., \& Strachan, N. (2010). Interactions and implications of renewable and climate change policy on UK energy scenarios. Energy Policy, 38(11), 6724-6735. doi: 10.1016/j.enpol.2010.06.042

[57] European Commission (EC) (2009). Decision No 406/2009/EC of the European Parliament and of the Council of 23 April 2009 on the effort of Member States to reduce their greenhouse gas emissions to meet the Community's greenhouse gas emission reduction commitments up to 2020. Brussels: European Commission (EC).

[58] DECC (2014). Green Book supplementary guidance: valuation of energy use and greenhouse gas emissions for appraisal. Retrieved from the GOV.UK website: https://www.gov.uk/government/publications/valuation-of-energy-use-and-greenhouse-gasemissions-for-appraisal

[59] DECC (2009). National Renewable Energy Action Plan for the United Kingdom. Retrieved from the GOV.UK website: https://www.gov.uk/government/uploads/system/uploads/attachment data/ file / 47871/25-nat-ren-energy-action-plan.pdf

[60] DECC (2014). UK National Energy Efficiency Action Plan. London: Department of Energy and Climate Change.

[61] European Commission (EC) (2011). Commission Staff Working Document: Impact Assessment Accompanying document to the Communication from the Commission to the European Parlia- 
ment, the Council, the European Economic and Social Committee and the Committee of the Regions: A Roadmap for moving to a competitive low carbon economy in 2050 \{COM(2011) 112 final\} \{SEC(2011) 289 final $\}$. Brussels: European Commission (EC).

[62] Anandarajah, G., Strachan, N., Ekins, P., Kannan, R., \& Hughes, N. (2009). Pathways to a Low Carbon Economy: Energy systems modelling. UKERC Energy 2050 Research Report 1, London.

[63] European Commission (EC) (2009). Directive 2009/28/EC of the European Parliament and of the Council of 23 April 2009 on the promotion of the use of energy from renewable sources and amending and subsequently repealing Directives 2001/77/EC and 2003/30/EC. Brussels: European Commission (EC).

[64] Fischer, C., \& Newell, R. G. (2008). Environmental and technology policies for climate mitigation. Journal of Environmental Economics and Management, 55(2), 142-162. doi: http://dx.doi.org/10. 1016/j.jeem.2007.11.001

[65] DECC (2014). Updated energy and emissions projections 2014. Retrieved from the GOV.UK website: https://www.gov.uk/government/uploads/system/uploads/attachment_data/file/368021/ Updated energy and emissions projections2014.pdf

[66] Pfenninger, S., \& Keirstead, J. (2015). Renewables, nuclear, or fossil fuels? Scenarios for Great Britain's power system considering costs, emissions and energy security. Applied Energy, 152, 83-93. doi: http://dx.doi.org/10.1016/j.apenergy.2015.04.102

[67] CCC (2011). The Renewable Energy Review. London: Committee on Climate Change.

[68] European Climate Foundation (2010). Roadmap 2050: A practical guide to a prosperous, lowcarbon Europe. Retrieved from the roadmap2050 website: http://www.roadmap2050.eu/ attachments/files/Volume1_fullreport_PressPack.pdf 


\section{Annex - Technology evolution in the energy-intensive sectors}

The figures below provide additional information on the technology deployment in the energyintensive sectors modelled in a process-oriented manner in UKTM. Note that usually only the technology choices for the most important production steps are shown. Also, only the technologies that are chosen are displayed in the figures (and not all that are actually modelled in UKTM).

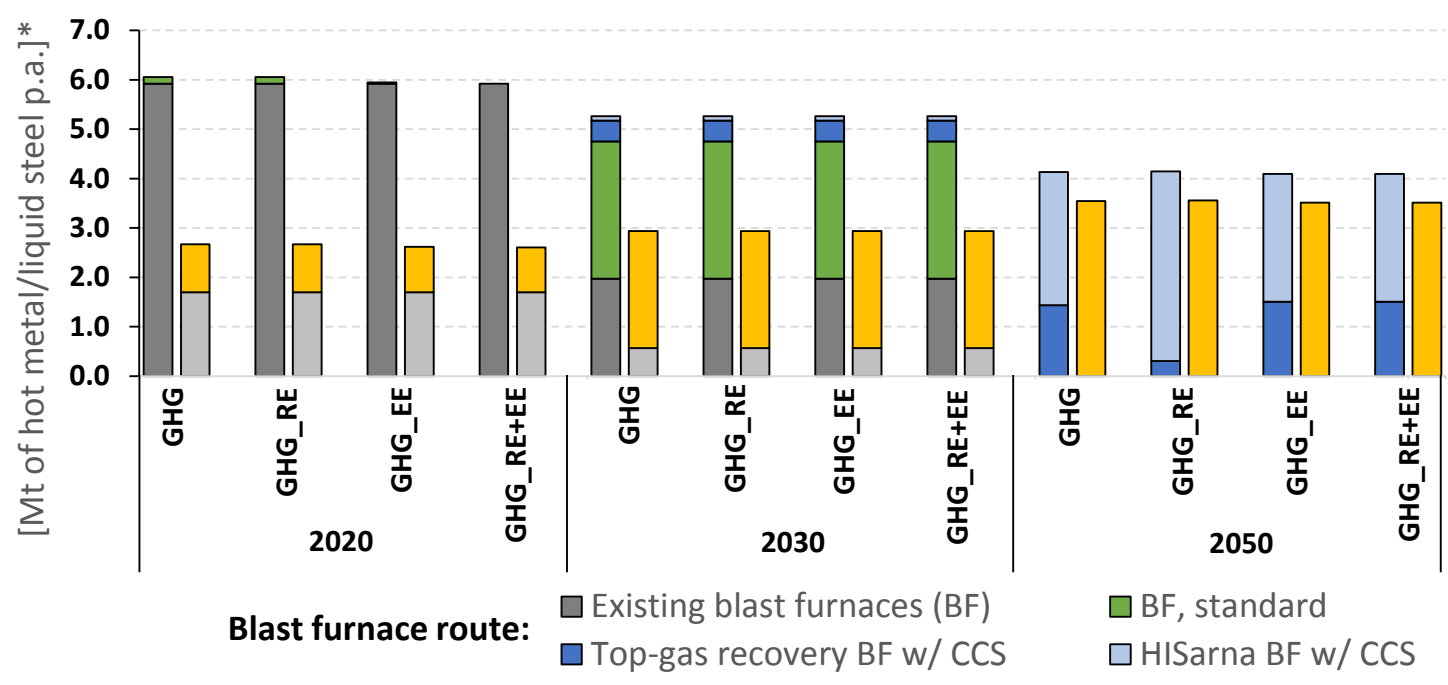

Electric arc furnace route: $\square$ Existing electric arc furnace (EAF) $\square$ Comelt EAF

* For the BF route, only the technologies for the production of hot metal in BF is shown (which is then processed to liquid steel in basic oxygen furnaces); for the EAF route the production of liquid steel is shown.

Figure A-1: Technology evolution in the iron and steel sector (blast and electric arc furnaces) in the lowcarbon scenarios

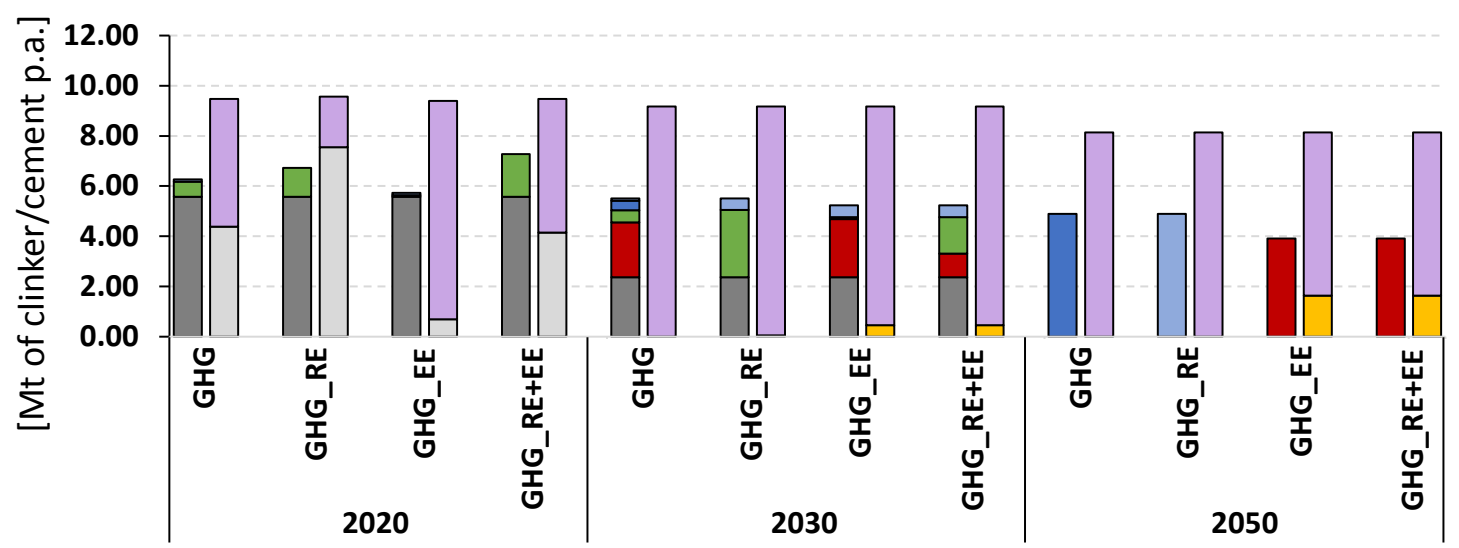

Clinker production:

$\square$ Fluidised bed kiln (FBK)

$\square$ BAT kiln w/MEA Post-comb. CCS

\section{Cement production:}

$\square$ Existing grinding \& mixing (G\&M) $\square$ Existing kilns

$\square$ FBK w/ increased waste use

$\square$ BAT kiln w/Partial Oxy-comb. CCS

$\square$ Low $\mathrm{CO} 2$ cements

$\square \mathrm{G} \& \mathrm{M} \mathrm{w} /$ increased clinker substitution

Figure A-2: Technology evolution in the cement sector in the low-carbon scenarios 


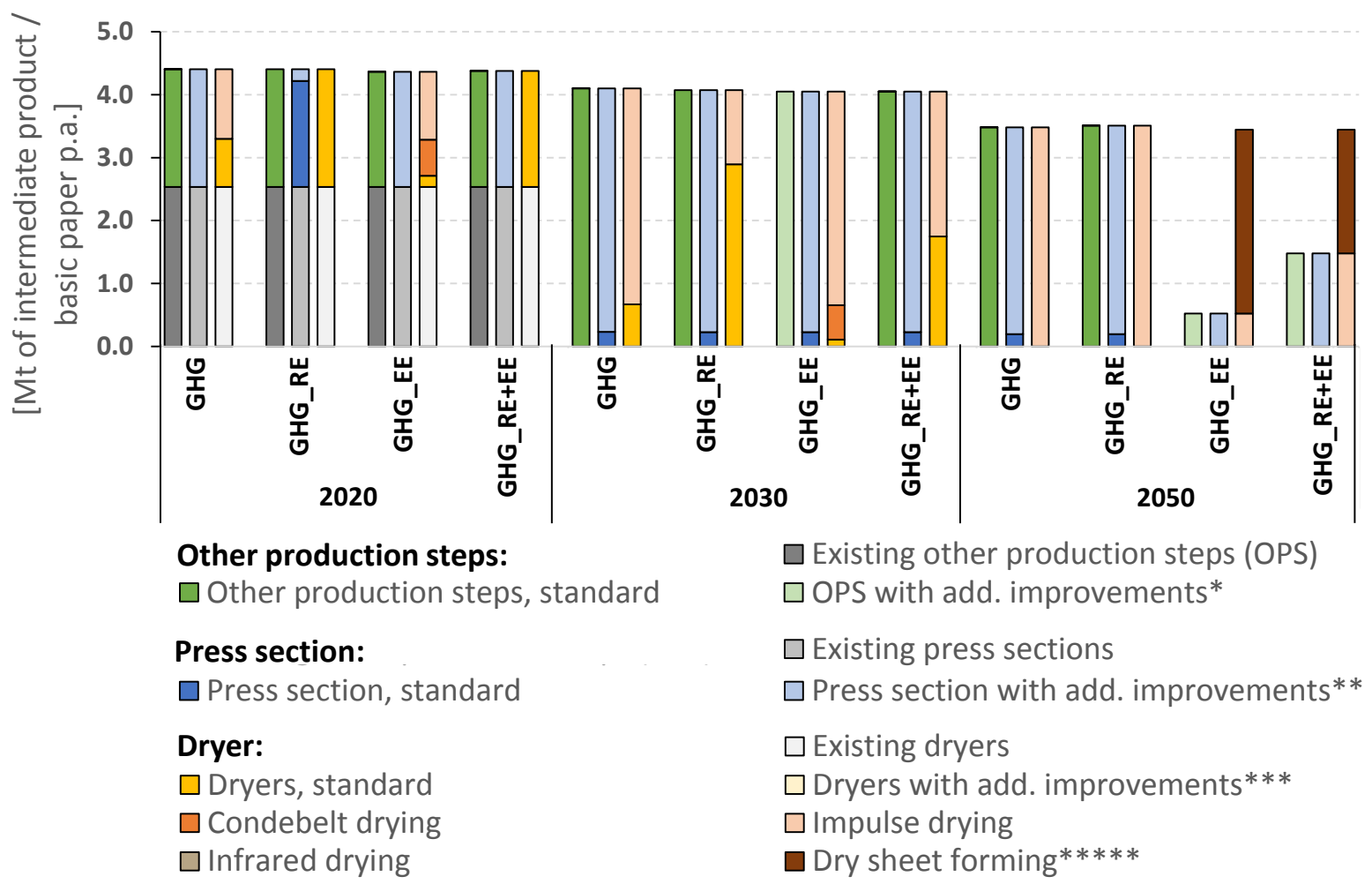

* Additional improvements (=add-ons improving existing technologies) for OPS modelled in UKTM are: (1) Online moisture management; (2) Other (covering average of using fans or blowers instead of vacuum where applicable, using turbo-compressors in place of vacuums in given situations; pumps and motors: match pumping capacity, aim for continuous flows, better control of flows.

** Additional improvements for press section modelled in UKTM are: (1) Aggregate (covering average of felt and belt design optimisation, monitoring press performance, turning off/reducing steam flow when not required, shoe pressing, minimising rewet, checking nip profiles \& optimising crowns, steam boxes use).

*** Additional improvements for dryer modelled in UKTM are: (1) Hot press; (2) Reducing air infiltration; (3) Maximizing hood humidity; (4) Efficiently using flash stream; (5) Maximizing heat recovery; (6) Other (average of avoiding steam venting, optimising pressures, felt design to optimise sheet contact, auto warm-up, using low pressure steam in place of high pressure, maximising condensate return, optimised dryer technology).

**** Alternative production route, covers all steps of basic paper production (OPS, press section \& dryer)

842 Figure A-3: Technology evolution in the paper sector (basic paper production) in the low-carbon scenarios

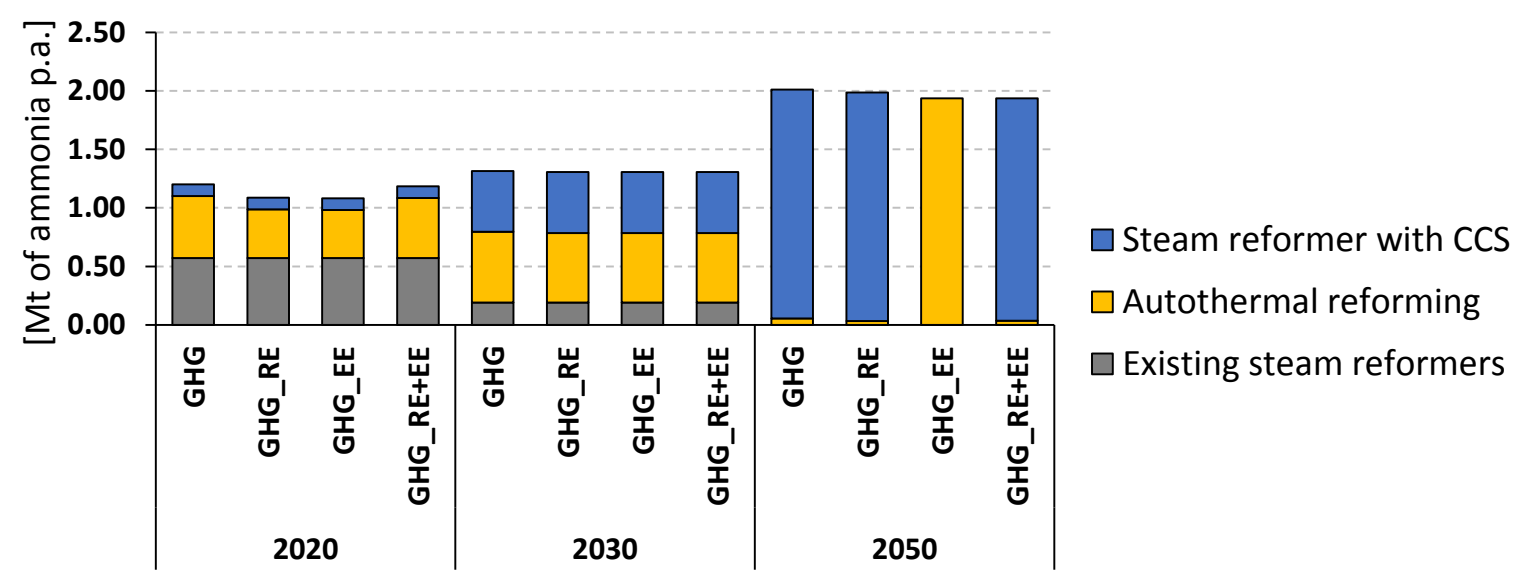

Figure A-4: Technology evolution for ammonia production in the low-carbon scenarios 


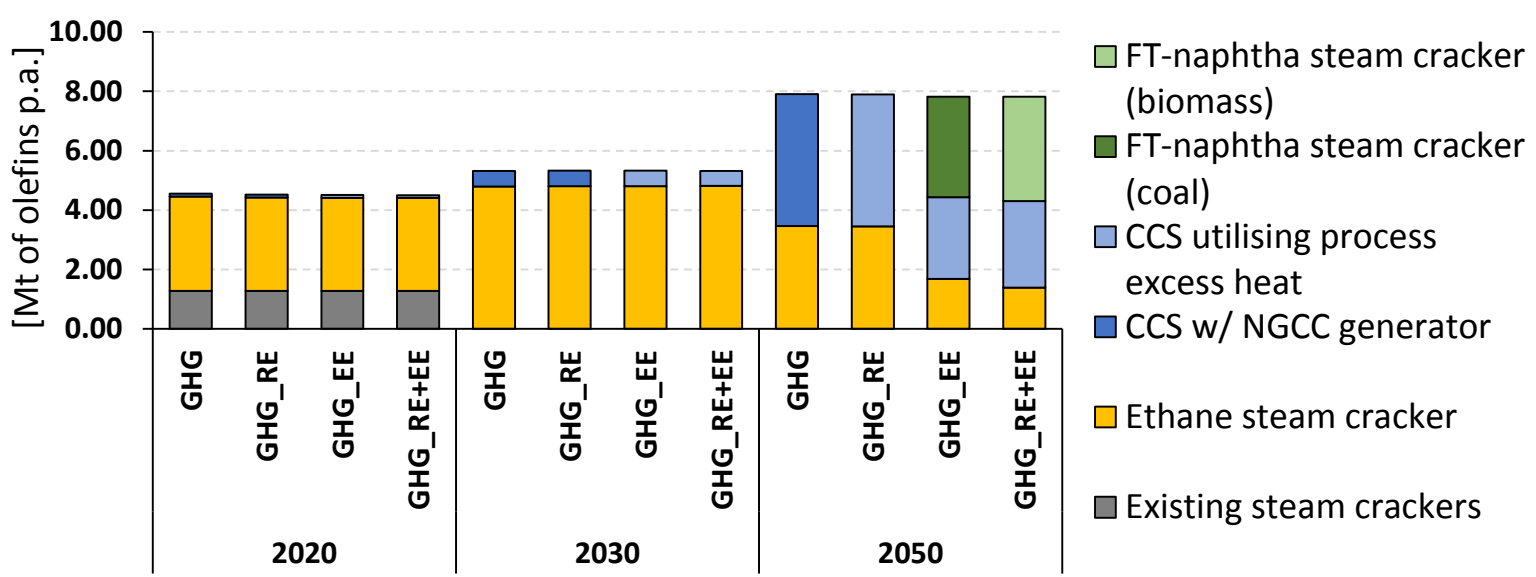

Figure A-5: Technology evolution for the production of high value chemicals (olefins) in the low-carbon scenarios 